molecule. Random cleavage would have liberated reducing di- and tri-saccharides in the verbascose solution and glucose at a much earlier stage in the verbascotetraose solution (see Fig. 1).

The $S$. bovis enzyme differs in one important aspect from all of the plant, yeast and mould $\alpha$ galactosidases. All of these latter enzymes have broad $\mathrm{pH}$ optima over the range $3 \cdot 5-5$ or 6 . $S$. bovis $\alpha$-galactosidase, however, has optimum activity over a narrow $\mathrm{pH}$ range $(5 \cdot 6-6 \cdot 3)$ and is inactive at $\mathrm{pH} 3 \cdot 0-4 \cdot 0$. The enzyme possesses normal transferase activity when the concentration of acceptor is above $1 \%$; melibiose, sucrose and raffinose act as acceptors. The compounds synthesized by transferase action were not isolated and examined chemically. The evidence from paper chromatograms, however, supports the conclusion that their formation involves galactosyl transfer to C-6 of the galactosyl unit of melibiose and raffinose or of the glucosyl unit of sucrose.

The properties of $S$. bovis $\alpha$-galactosidase with regard to $\mathrm{pH}$ and temperature optima reflect the conditions of the organism's natural habitat in the rumen. Likewise substrate specificity is in agreement with the known occurrence of raffinose and galactosylgalactosylglycerol in many pasture plants. Apart from any interest in the enzyme itself it should be of value in structural studies on some of the more complex naturally occurring galactosylsucroses, particularly as, provided that phosphate is absent, the extract does not hydrolyse sucrose.

\section{SUMMARY}

1. Cell extracts prepared from a rumen strain of Streptococcus bovis grown on glucose contain $\alpha$ galactosidase, amylase, sucrose phosphorylase and occasionally isomaltase, but no other carbohydrases.

2. In the absence of phosphate sucrose is not hydrolysed and sugars of the raffinose series are hydrolysed to galactose and sucrose.

3. The $\alpha$-galactosidase readily hydrolyses melibiose and other oligosaccharides containing $\alpha-(1 \rightarrow 6)$ linked galactose, but only hydrolyses methyl $\alpha$-Dgalactoside, melibi-itol and manninotri-itol slowly; methyl $\beta$-L-arabinopyranoside and 4- $O-\alpha$-D-galactosyl-D-galactose are not hydrolysed.

4. The enzyme has optimum activity in the $\mathrm{pH}$ range $5 \cdot 6-6 \cdot 3$ and temperature range $37-42^{\circ}$.

5. It may act as a transferase giving, with melibiose, sucrose or raffinose as acceptors, a single tri- or tetra-saccharide.

The gift of sugar by Professor R. L. Whistler is gratefully acknowledged, and also the technical assistance of Miss V. Turner and Mrs B. Eglington.

\section{REFERENCES}

Bailey, R. W. (1962). Nature, Lond., 195, 79.

Bailey, R. W. \& Bourne, E. J. (1961). Nature, Lond., 191, 277.

Bailey, R. W. \& Oxford, A. E. (1958). J.gen. Microbiol. 19, 130.

Bailey, R.W.\& Roberton, A. M. (1962). Biochem.J. 82, 272.

Carrere, C., Lambin, S. \& Courtois, J. E. (1960). C.R. Soc. biol., Paris, 154, 1747.

Huggett, A. St G. \& Nixon, D. A. (1957). Lancet, 273, 368.

Mollvaine, T. C. (1921). J. biol. Chem. 49, 183.

Nelson, N. (1944). J. biol. Chem. 153, 375.

Nossal, P. M. (1953). Aust. J. exp. Biol. 31, 583.

Wallenfels, K. \& Malhotra, O. P. (1961). Advanc. Carbohyd. Chem. 16, 239.

Weenink, R. O. (1961). J. Sci. Fd Agric. 12, 34.

Wintermans, J. G. F. M. (1960). Biochim. biophys. Acta, 44, 49.

Biochem. J. (1963) 86, 514

\title{
The Crystal Structure of Phenoxymethylpenicillin
}

\author{
By S. ABRAHAMSSON,* DOROTHY CROWFOOT HODGKIN AND E. N. MASLEN $\dagger$ \\ Laboratory of Chemical Crystallography, Oxford
}

(Received 23 August 1962)

Phenoxymethylpenicillin [penicillin V, (I)] was first prepared and its formula established by Behrens, Corse \& Edwards (1948). Its potential use in the oral administration of penicillin was not

* Present address: Institute of Medical Biochemistry, University of Gothenberg, Sweden.

$\dagger$ Present address: Physics Department, University of Western Australia. realized until Brandl \& Margreiter (1954) showed that it was much more stable to acids than other then known penicillins. The free acid itself is unusual among penicillins in being easily crystallizable in a solvent-free state.

Brandl \& Margreiter (1954) suggested that these unexpected properties might be caused by some conformational change within the molecule which 
<smiles>CC(C)C1SC2C(NC(=O)COc3ccccc3)CON12</smiles>

(I)

could permit hydrogen bonding, e.g. between the $\beta$-lactam oxygen atom and the side-chain $\mathrm{CH}_{2}$ or $\mathrm{NH}$ group. Crystallographic studies were therefore undertaken to investigate the geometrical characteristics of the compound, both as the sodium salt and as the free acid. Preliminary work on the sodium salt (Hurdman, 1959) showed that the phenoxymethylpenicillin ion was very similar in conformation to benzylpenicillin. The present study is concerned with the $\mathrm{X}$-ray analysis in greater detail of crystals of the free acid, phenoxymethylpenicillin.

\section{EXPERIMENTAL}

Brandl \& Margreiter (1954) described the crystallization of penicillin V, among other ways, from acetone solutions on the addition of water. This method was used to grow crystals for the X-ray analysis. A solution of the free acid in acetone was introduced into a capillary tube and water was added slowly at the surface of the acetone solution. Small crystals thus formed sank through the liquid, growing rapidly as more water was added. In this way, crystals were obtained varying from about $\frac{1}{2} \mathrm{~mm}$. Iong in the lower part of the tube to an almost microcrystalline mass higher up. They occurred in two forms, according to their rate of growth: diamond-shaped plates on $\{001\}$ and monoclinic sphenoids. Both varieties were used in the $\mathrm{X}$-ray analysis.

\section{Crystal data}

The crystal data for phenoxymethylpenicillin

$$
\left(\mathrm{C}_{18} \mathrm{H}_{18} \mathrm{~N}_{2} \mathrm{O}_{5} \mathrm{~S}, M=350 \cdot 4\right)
$$

may be summarized as follows: monoclinic sphenoidal,

$$
\begin{array}{ll}
a=12 \cdot 79 \pm 0.02 \AA, & b=11 \cdot 236 \pm 0 \cdot 007 \AA, \\
c=13 \cdot 39 \pm 0 \cdot 02 \AA, & \beta=115^{\circ} 44^{\prime} \pm 6^{\prime}, \\
V=1733 \cdot 6 \AA^{8}, & D_{\mathrm{m}}=1 \cdot 367, \\
Z=4, & D_{\mathrm{c}}=1 \cdot 343, \\
F(000)=736, &
\end{array}
$$

space group C2. Copper $K_{\alpha}$-radiation was used; oscillation and Weissenberg photographs were taken about the $a, b$ and [110] axes.

\section{Collection of intensity data}

Initially, small crystals were selected $(0.3 \mathrm{~mm} . \times 0.2 \mathrm{~mm}$. $\times 0.1 \mathrm{~mm}$.) and Weissenberg photographs were taken about the $b$ axis. For correlation, a series of photographs of the layers 0-7 about the [110] axis was then taken with a larger crystal $(0.6 \mathrm{~mm} . \times 0.3 \mathrm{~mm} . \times 0.3 \mathrm{~mm}$.).

Comparison of the two sets showed that the crystals underwent slow decomposition in the X-ray beam. Marked variation was found in the intensities of reflexions from crystals which had been in the beam for some time, though the correlation was good for reflexions from fresh crystals. The $b$-axis series was therefore rephotographed with three larger crystals to compare with the [110] series, and a further correlating $a$-axis zero-layer Weissenberg photograph was also recorded.

The first two series of intensities were estimated visually by using a scale. The rephotographed $b$-axis series was measured with a microdensitometer, together with the $a$-axis photograph and the first four layers of the [110] series. Spot-shape variations were serious and were corrected as follows. The areas of a representative number of spots were measured as accurately as possible and, from these measurements, graphs were drawn giving the variation of spot shape with the co-ordinate on the film. From these graphs, the area of each spot was estimated by interpolation and the product of the density and area was taken as proportional to the intensity. The results agreed well with the visual measurements.

In all, some 2400 reflexions were measured. Their intensities were corrected for Lorentz and polarization factors and so reduced to relative $F^{2}$ values with the help of a programme designed for the English Electric Co. computer, Deuce. No absorption corrections were applied. Wilson plots were performed for the different layers and it was found that $B$ increased with the time the crystal had been in the X-ray beam. The data of the 'older' crystals were corrected to show the same temperature factor as fresh crystals, and relative scale factors were obtained from common reflexions. The whole set of data, relative $F^{2}$ values derived from 1670 independent reflexions, was placed on an absolute scale by a three-dimensional Wilson plot. For the temperature factor of fresh crystals, the value of 3.5 was found for $B$.

\section{Structure determination}

The structure was determined from a three-dimensional Patterson distribution calculated with the experimental, approximately absolute, $F^{2}$ values modified to correspond with those from point atoms at rest.

The modification function employed was chosen as the result of a study of the effects of various functions on the shape of peaks in Patterson series (Abrahamsson \& Maslen, 1960, and unpublished work). This study indicated that, in the three-dimensional case, a high weight could be given to the outer terms without serious trouble from diffraction ripples, and that this weighting both increased the resolution of the peaks ('sharpening' effect) and also favourably enhanced vectors due to moderately heavy atoms such as sulphur in the presence of light atoms. Fig. 1 shows some of the peak shapes calculated in relation to penicillin $V$. Even with outer terms given 50 times higher weight than inner ones, the first diffraction minimum is less than $20 \%$ of the peak height. At the same time the relative height of the S-S vector peak is increased considerably (cf. Hodgkin \& Maslen, 1961).

In the structure analysis of penicillin $V$, the first threedimensional Patterson synthesis calculated on Deuce was based on only slightly sharpened coefficients corresponding approximately to $\mathrm{A}$ in Fig. 1. Its Harker section (Fig. 2) showed three prominent peaks, $A, B$ and $C$, of which $C$ could be excluded as a S-S vector owing to its proximity to the twofold axis. An attempt was made to solve the structure by relating the remaining peak positions with the S-S vector based on either $A$ or $B$. In both cases, it seemed 


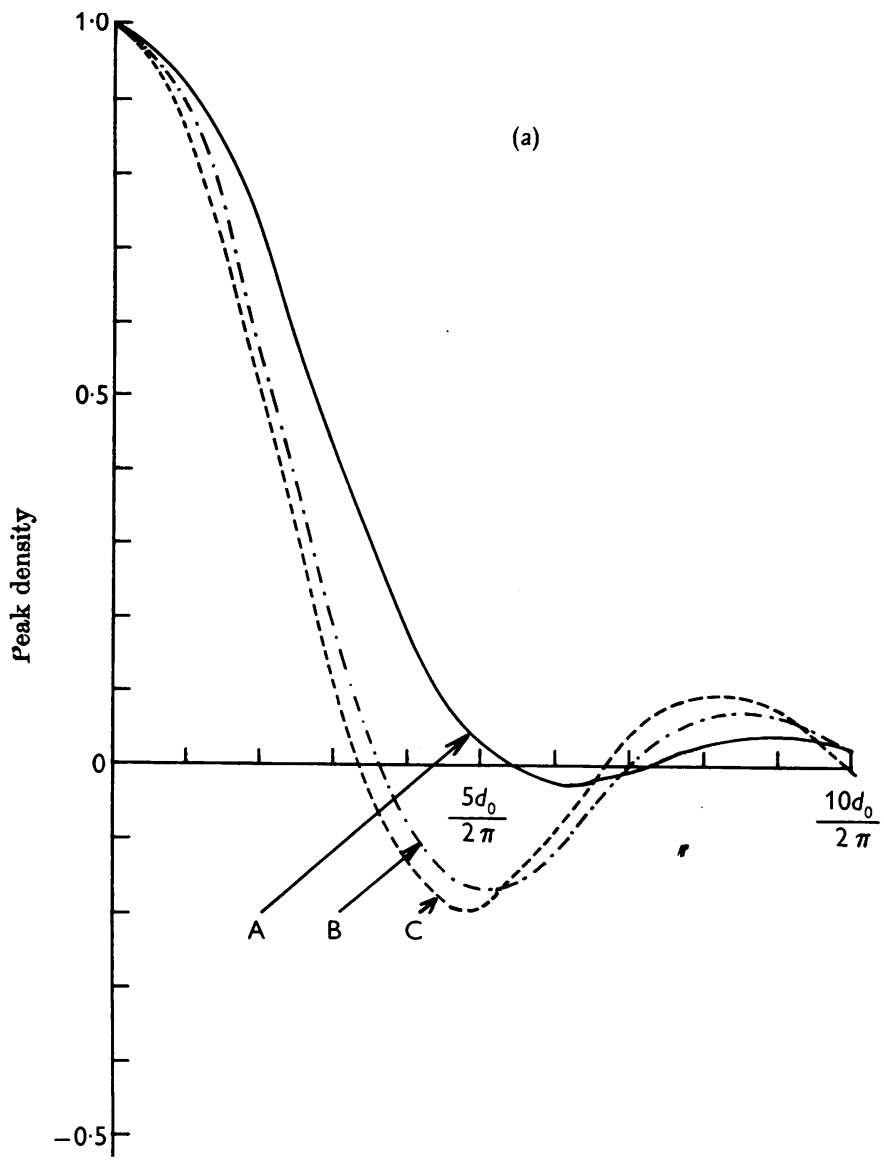

(b)

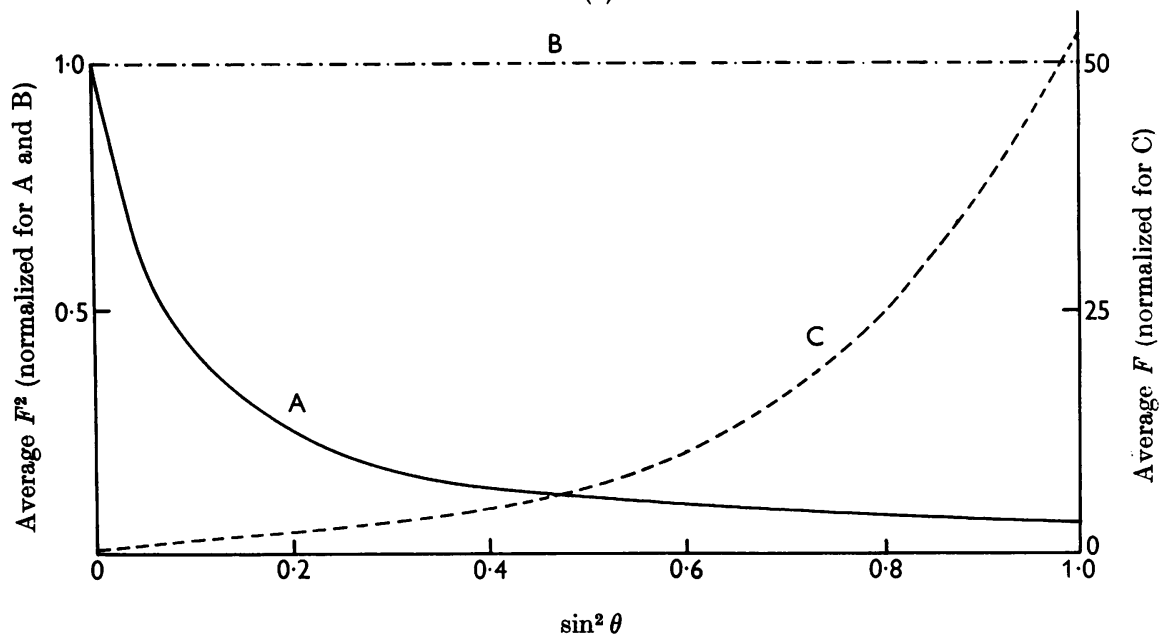

Fig. 1. Patterson peak shapes normalized to unity for phenoxymethylpenicillin $(a)$ and their corresponding net distribution of coefficients $(b)$. A $(-)$ : the sharpening function $M(\mathrm{~S})=\exp \left(B \mathrm{~S}^{2} / 2\right)$; atoms at rest; $\mathrm{S}-\mathrm{S}: \mathrm{O}-\mathrm{O}$ ratio $=6 \cdot 5$. B $(-\cdot-\cdot)$ : the sharpening function $M(\mathrm{~S})=1 / f(\mathrm{~S}) \exp \left(B \mathrm{~S}^{2} / 2\right)$; point atoms at rest; S-S:0-0 ratio $=8 \cdot 5$. C $(-\ldots)$ : the sharpening function $M(S)=1 / f(S) \exp \left(B \mathrm{~S}^{2} / 2\right) \exp \left(2 \cdot 35 \mathrm{~S}^{2}\right)$; divergent sharpening; $\mathrm{S}-\mathrm{S}: 0-0$ ratio $=9 \cdot 1$. 
possible to relate many more peaks than there were atoms. The difficulty largely arose from the very heavy concentration of vectors in the [201] plane.

The situation became much clearer when the Patterson series was recalculated with terms modified as in B in Fig. 1. The Harker section (Fig. 3) showed $A$ as the most prominent peak and it seemed certain that this was the $\mathrm{S}-\mathrm{S}$ vector. The three-dimensional distribution was therefore investigated throughout to identify the S-light atom vectors. Peaks down to one-sixth of the origin height were picked out and examined mathematically to find pairs related by the S-S vector. Thirty-one such pairs were found which give the combined peak distribution shown in Fig. 4. The sulphur atom here is arbitrarily given the $y$ coordinate 0 . The sign of the $y$ co-ordinates for the other atoms was initially indeterminate. However, by using
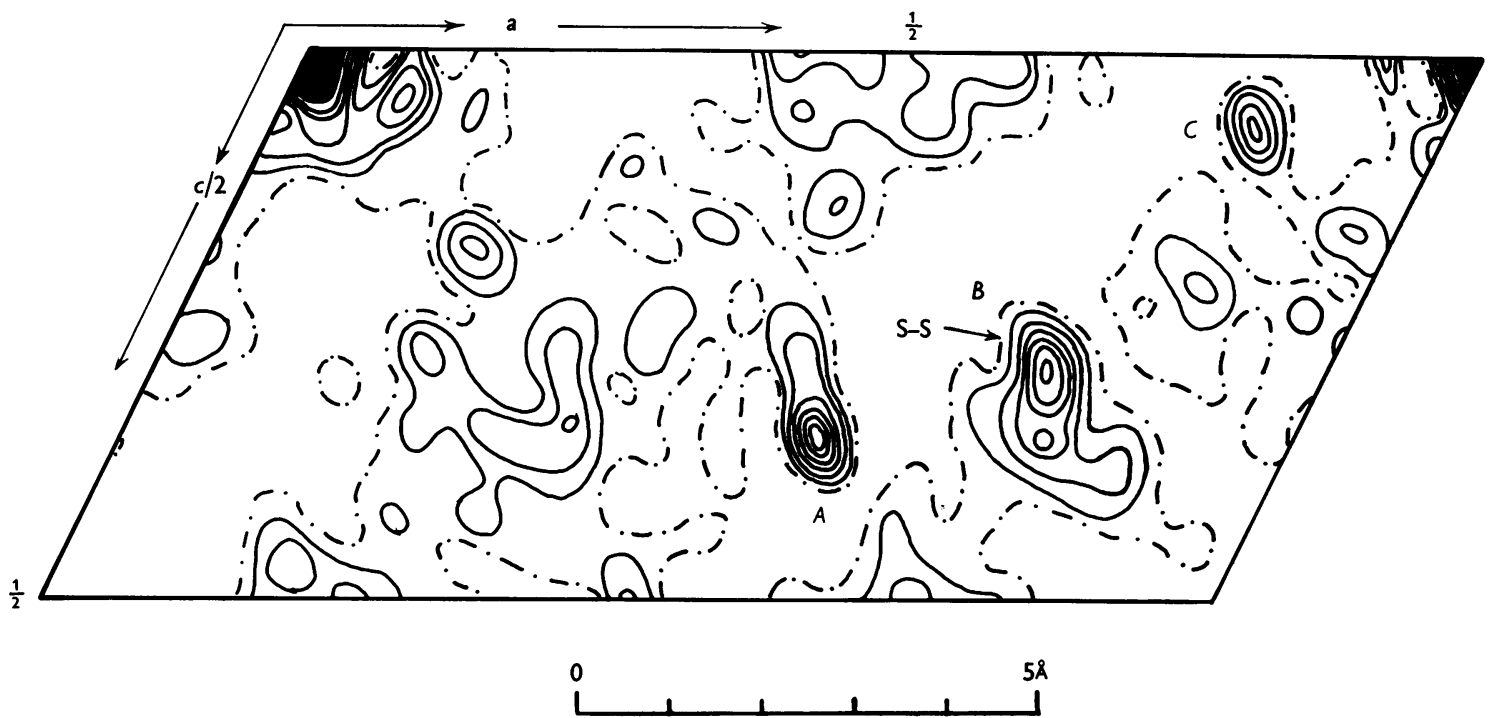

Fig. 2. Harker section, $P(x 0 z)$, of phenoxymethylpenicillin; the coefficients are sharpened to 'atoms at rest'.
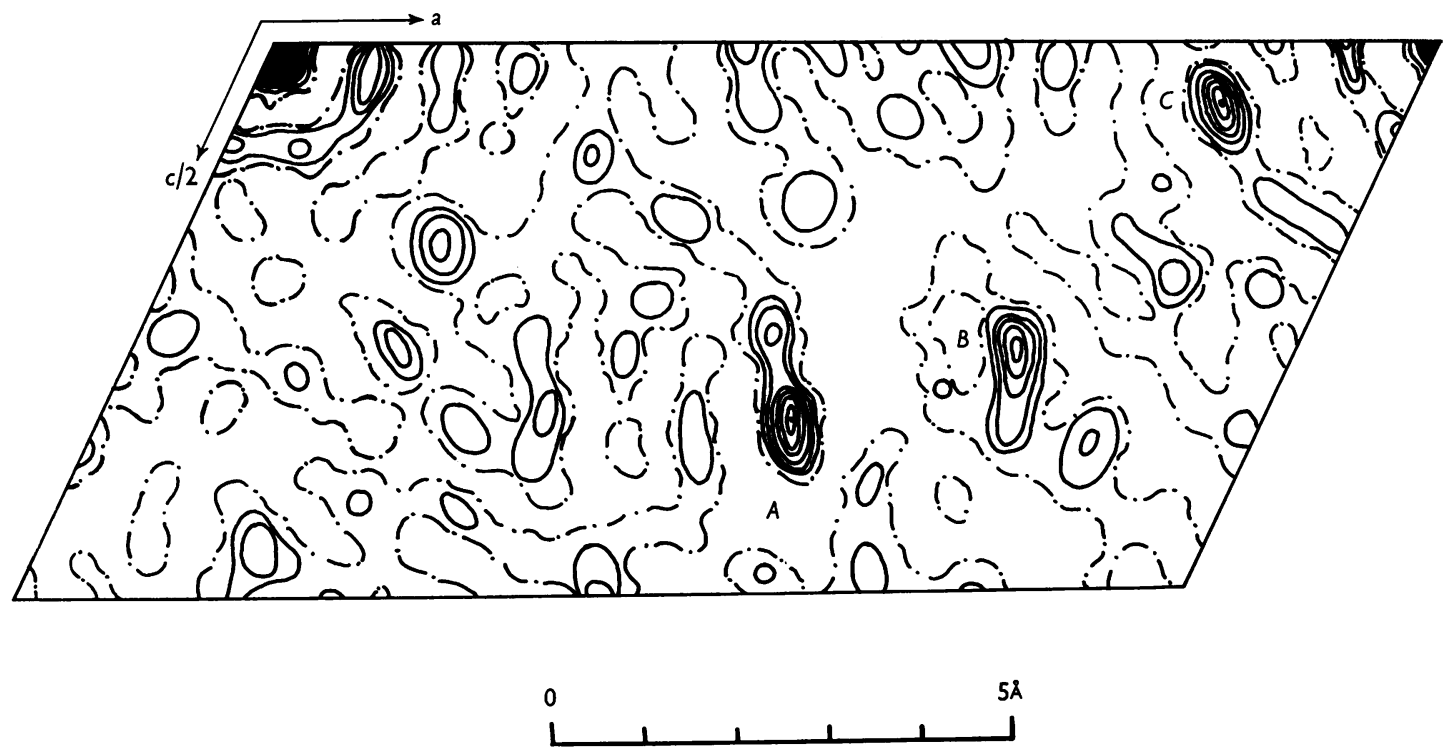

Fig. 3. Harker section, $P(x 0 z)$, of phenoxymethylpenicillin; the coefficients are sharpened to point atoms at rest. $\mathrm{S}$-light atom vectors in or close to the section. 
normal bond lengths and bond angles, it was easy to fit the whole molecule over the peak pattern except for one atom. Of the observed coincidences nine did not correspond to the atomic positions but they never disturbed the fitting of the molecule.

It is clear that, in the 'point atoms at rest' synthesis, the solution of the Patterson distribution is simplified since the aggregrates of light atom-light atom vectors are broken up and their relative heights reduced. The synthesis is equally powerful if the vector-correlation process used to define atomic positions is carried out by formal superposition methods. Fig. 5 shows the section at $y=0$ for penicillin $\mathrm{V}$ derived from a superposition programme written for the Mercury computer to give Buerger's minimum function. Although it is based on the sharpened Patterson distribution and the sulphur atom positions only, it is extremely close to the corresponding electron-density section, later evaluated (see below).

\section{Structure refinement}

For the first structure-factor calculation all atoms were included except those of the carboxyl group of which one atom was missing in the Patterson distribution obtained. For sulphur the scattering curve of Viervoll \& Ögrim (1949) was used, and for carbon, nitrogen and oxygen those of Berghuis et al. (1955). Programmes for the computer Mercury were those described by Mills \& Rollett (1961).

A three-dimensional electron-density series calculated on the first structure-factor set gave the remaining atoms. Their co-ordinates and the $n$-shifted $(n=1 \cdot 75)$ coordinates of the other atoms were found from the maps by a 19-point computer programme written by Dr R. Sparks. A second round of Fourier refinement was performed and then anisotropic least-squares refinement was started. In this refinement, each atom was assigned three co-ordinates defining its position and also parameters to account for its apparent anisotropic thermal vibration within the crystal (cf. Lipson \& Cochran, 1953). The quantity $\Sigma \omega\left(F_{0}-F_{0}\right)^{2}$ was minimized where:

$$
\omega=\frac{1}{1+\left[\left(\left|F_{0}\right|-8|F|_{\text {min. }}\right) / 6|F|_{\text {min. }]^{2}}\right.}
$$

At the third round of least-squares calculations, hydrogen atoms on those carbon atoms which showed normal tetrahedral or trigonal angles were included in the structure-factor calculations with positions found with programmes for the Mercury computer written by Dr Sparks. Their parameters were not refined.

At one stage the least-squares refinement was checked by comparison with a difference synthesis. Shifts indicated in positional and thermal parameters were in general agreement with those suggested by the least-squares round. At the sixth round of least-squares refinement shifts were about one-tenth of the estimated standard deviations and the refinement was stopped. The $R$ value was then $12.6 \%$ for all observed reflexions.

A difference synthesis was calculated on the structure factors at this stage to try to locate the hydrogen atoms not included in the structure-factor calculations. These hydrogen atoms were two attached to $C(6)$ and $C(7)$, one attached to the amide $\mathrm{N}(14)$ and one expected near the carboxyl oxygen, $\mathrm{O}(13)$. Peaks show up at all the positions; they cannot, however, be quoted as good evidence for the presence of hydrogen atoms at these sites since there are still background fluctuations in the electron distributions of about $0 \cdot 7 e / \AA^{3}$, which are of the same order of magnitude.

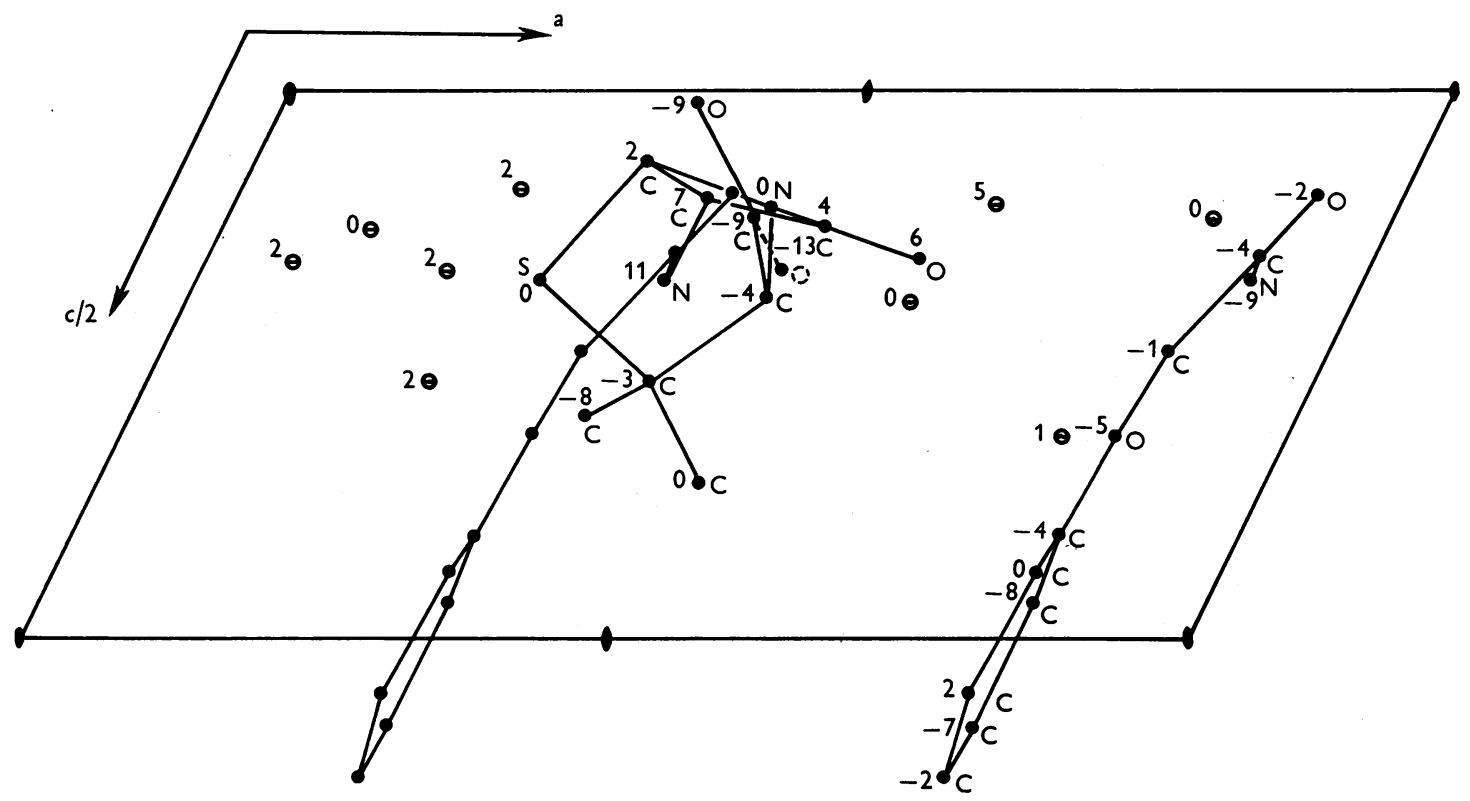

Fig. 4. Distribution of possible atomic positions in phenoxymethylpenicillin derived from the Patterson series. The structure is shown projected on (010); the figures indicate the $y$ parameters as fortieths of $b$. $\theta$, Spurious peak. With the method used, $\mathbf{O}(18)$ (broken line) was not found. 


\section{RESULTS AND DISCUSSION}

The final positional parameters of the atoms and the estimated standard deviations are given in Table 1, the vibrational parameters in Table 2 and the observed and calculated structure factors in Table 3.

The bond lengths and angles within the molecule are recorded in Table 4 and illustrated in Fig. 6.
With the usual formula (Cruickshank \& Robertson, (1953) standard deviations, $\sigma$, in the bond lengths were calculated by using average values for positional deviations and approximating these to be independent of direction:

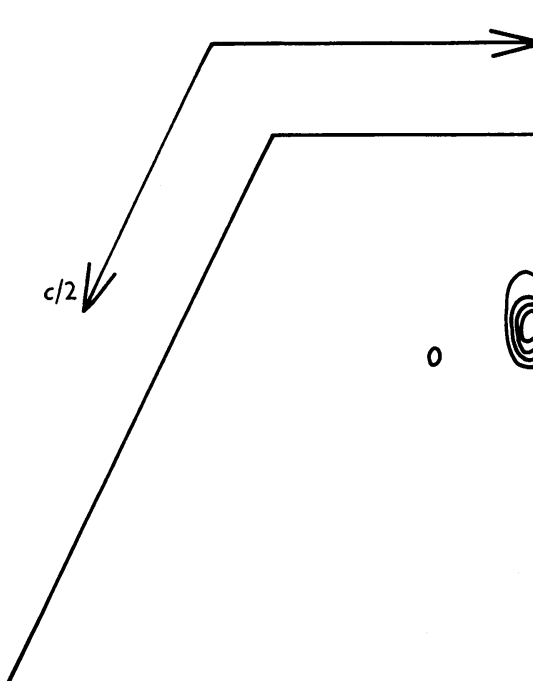

(a)

$$
\begin{aligned}
& \sigma(\mathrm{S}-\mathrm{C})=0.016 \AA ; \\
& \sigma(\mathrm{C}-\mathrm{O})=\sigma(\mathrm{C}-\mathrm{N})=0.018 \AA ; \\
& \sigma(\mathrm{C}-\mathrm{C})=0.021 \AA .
\end{aligned}
$$

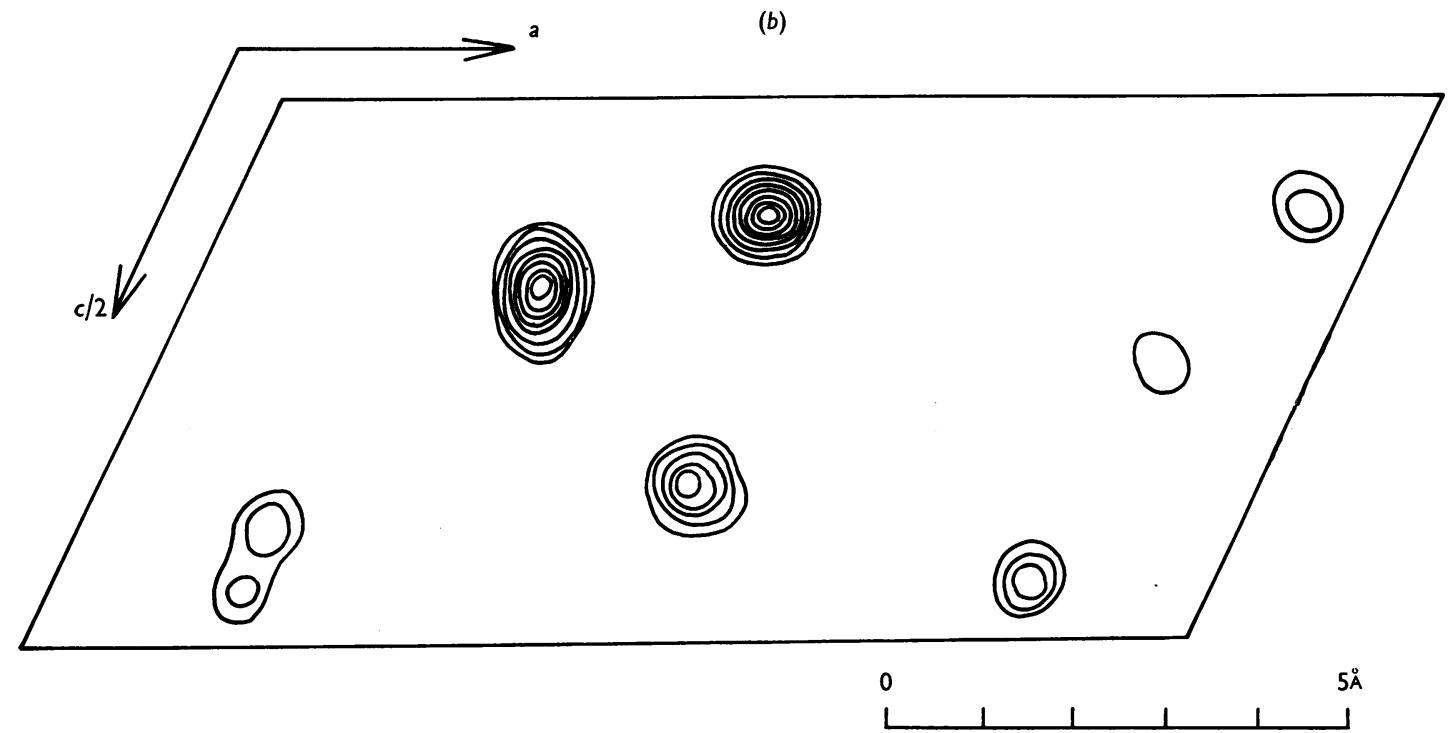

Fig. 5. (a) Section $y=0$ of the minimum function based on the sulphur positions in the phenoxymethylpenicillin molecule compared with $(b)$ the corresponding section in the final electron-density distribution. The scale of the minimum function is arbitrary. The electron-density map is contoured at intervals of $l e / \mathbf{A}^{3}$ starting at the $2 e$ level, except over the sulphur atom where the contours are at $4 e / \AA^{3}$. Owing to the sharpness of the Patterson series, only the atoms close to $y=0$ show up in the minimum function. 
Table 1 (a). Atomic co-ordinates (fractional) of phenoxymethylpenicillin

\begin{tabular}{|c|c|c|c|}
\hline Atom & $x / a$ & $y / b$ & $z / c$ \\
\hline $\mathrm{S}(\mathbf{1})$ & $0 \cdot 2967$ & 0.0022 & $0 \cdot 1746$ \\
\hline $\mathrm{C}(2)$ & 0.4316 & -0.0839 & $0 \cdot 2583$ \\
\hline$C(3)$ & 0.4886 & -0.1079 & $0 \cdot 1770$ \\
\hline$N(4)$ & 0.4611 & -0.0016 & $0 \cdot 1075$ \\
\hline$C(5)$ & 0.3450 & $0 \cdot 0606$ & 0.0745 \\
\hline$C(6)$ & 0.4017 & $0 \cdot 1879$ & 0.0880 \\
\hline$C(7)$ & 0.5162 & $0 \cdot 1149$ & $0 \cdot 1320$ \\
\hline$O(8)$ & 0.6185 & $0 \cdot 1381$ & 0.1743 \\
\hline$C(9)$ & 0.5119 & -0.0091 & $0 \cdot 3547$ \\
\hline$C(10)$ & $0 \cdot 3943$ & $-0 \cdot 2023$ & $0 \cdot 2983$ \\
\hline$C(11)$ & 0.4462 & $-0 \cdot 2243$ & 0.1108 \\
\hline $\mathrm{O}(12)$ & 0.5039 & $-0 \cdot 3233$ & $0 \cdot 1630$ \\
\hline$O(13)$ & $0 \cdot 3667$ & $-0 \cdot 2270$ & 0.0190 \\
\hline$N(14)$ & $0 \cdot 3886$ & $0 \cdot 2632$ & 0.1688 \\
\hline$C(15)$ & $0 \cdot 3917$ & 0.3847 & $0 \cdot 1695$ \\
\hline$O(16)$ & 0.4187 & 0.4489 & $0 \cdot 1040$ \\
\hline$C(17)$ & $0 \cdot 3585$ & 0.4520 & $0 \cdot 2477$ \\
\hline$O(18)$ & $0 \cdot 3384$ & 0.3619 & $0 \cdot 3169$ \\
\hline$C(19)$ & $0 \cdot 3414$ & $0 \cdot 4007$ & 0.4172 \\
\hline$C(20)$ & 0.3445 & $0 \cdot 3043$ & 0.4870 \\
\hline $\mathrm{C}(21)$ & $0 \cdot 3450$ & $0 \cdot 3375$ & 0.5904 \\
\hline $\mathrm{C}(22)$ & $0 \cdot 3390$ & 0.4554 & 0.6160 \\
\hline$C(\mathbf{2 3})$ & $0 \cdot 3367$ & 0.5475 & 0.5475 \\
\hline $\mathrm{C}(24)$ & 0.3350 & 0.5246 & 0.4405 \\
\hline $\mathbf{H}(3)$ & $0 \cdot 5809$ & -0.1116 & $0 \cdot 2266$ \\
\hline $\mathbf{H}\left(9^{\prime}\right)$ & 0.4696 & 0.0114 & $0 \cdot 4091$ \\
\hline $\mathbf{H}\left(9^{\prime \prime}\right)$ & 0.5893 & -0.0555 & 0.4036 \\
\hline $\mathbf{H}\left(\mathbf{9}^{\prime \prime \prime}\right)$ & 0.5369 & 0.0768 & $0 \cdot 3274$ \\
\hline $\mathbf{H}\left(10^{\prime}\right)$ & $0 \cdot 4684$ & -0.2535 & $0 \cdot 3449$ \\
\hline $\mathrm{H}\left(10^{\prime \prime}\right)$ & $0 \cdot 3316$ & -0.2569 & $0 \cdot 2267$ \\
\hline $\mathrm{H}\left(10^{m \prime \prime}\right)$ & $0 \cdot 3487$ & -0.1857 & $0 \cdot 3502$ \\
\hline $\mathbf{H}\left(1 \mathbf{1 7}^{\prime}\right)$ & $0 \cdot 4268$ & 0.5118 & $0 \cdot 2985$ \\
\hline $\mathbf{H}\left(17^{\prime \prime}\right)$ & 0.2755 & 0.4993 & $0 \cdot 1982$ \\
\hline $\mathbf{H}(20)$ & 0.3462 & $0 \cdot 2088$ & $0 \cdot 4630$ \\
\hline $\mathrm{H}(21)$ & $0 \cdot 3536$ & $0 \cdot 2676$ & 0.6520 \\
\hline $\mathbf{H}(22)$ & $0 \cdot 3383$ & 0.4757 & $0 \cdot 6950$ \\
\hline $\mathrm{H}(23)$ & $0 \cdot 3381$ & $0 \cdot 6382$ & 0.5790 \\
\hline H(24) & 0.3292 & 0.5970 & 0.3825 \\
\hline
\end{tabular}

For the bond angles (C-C-C) the deviation was estimated to be of the order of $1 \cdot 5^{\circ}$. These values are clearly too small compared with the range of values for distances and angles actually found in the benzene ring $\left(1 \cdot 38-1 \cdot 45 \AA ; 115-126^{\circ}\right)$. This may be partly due to the fact that, in the standard formula, the covariances are neglected; these are likely to be large since the axes are not orthogonal. The reliability of the molecular parameters is of the same order as that reached by J. S. Rollett and A. Vaciago (personal communication) in a refinement of the structure of potassium benzylpenicillin from results obtained by Pitt (1952). In both crystal structures, the quality of the intensity data seriously limits the accuracy that can be achieved.

The bond lengths observed within the molecule and the packing of the molecules in the crystal indicate that the phenoxymethylpenicillin molecule is present as the free carboxylic acid. The packing relations are illustrated in Fig. 7. As in the crystal structure of potassium benzylpenicillin (Crowfoot, Bunn, Rogers-Low \& Turner-Jones, 1949), the molecules make contact with one another in alternate layers which contain either the hydrocarbon parts of the molecule (benzene rings and methyl groups) or the polar groups. Details of the

Table $1(b)$. Estimated standard deviations of atomic co-ordinates of phenoxymethylpenicillin molecule

\begin{tabular}{clll} 
Atom & \multicolumn{1}{c}{$\sigma(x)(\AA)$} & \multicolumn{1}{c}{$\sigma(y)(\AA)$} & \multicolumn{1}{c}{$\sigma(z)(\AA)$} \\
$\mathrm{C}$ & $0.012-0.016$ & $0.015-0.022$ & $0.012-0.017$ \\
$\mathrm{~N}$ & $0.011-0.012$ & $0.012-0.015$ & 0.010 \\
$\mathrm{O}$ & $0.011-0.012$ & $0.010-0.013$ & $0.010-0.012$ \\
$\mathrm{~S}$ & 0.003 & 0.005 & 0.004
\end{tabular}

Table 2. Allowance made for anisotropic thermal motion in the phenoxymethylpenicillin molecule with:

$$
\exp \left[10^{-5}\left(b_{11} h^{2}+b_{22} k^{2}+b_{33} l^{2}+b_{23} k l+b_{13} h l+b_{12} h k\right)\right]
$$

\begin{tabular}{|c|c|c|c|c|c|c|}
\hline Atom & $b_{11}$ & $b_{\mathbf{2 z}}$ & $b_{33}$ & $b_{23}$ & $b_{13}$ & $b_{12}$ \\
\hline$S(1)$ & 451 & 1149 & 821 & 106 & 862 & 2 \\
\hline$C(2)$ & 549 & 1237 & 659 & -69 & 882 & -192 \\
\hline$C(3)$ & 458 & 1181 & 715 & -14 & 735 & -186 \\
\hline$N(4)$ & 589 & 1377 & 456 & -62 & 673 & -26 \\
\hline$C(5)$ & 544 & 1063 & 594 & 414 & 616 & 417 \\
\hline C(6) & 570 & 1078 & 403 & -42 & 272 & -280 \\
\hline$C(7)$ & 872 & 1090 & $\mathbf{3 7 8}$ & 47 & 821 & 99 \\
\hline$O(8)$ & 613 & 1219 & 1051 & -144 & 1153 & -366 \\
\hline$C(9)$ & 850 & 1789 & 495 & -89 & 698 & -143 \\
\hline $\mathrm{C}(10)$ & 1077 & 1112 & 1109 & 433 & 1664 & 54 \\
\hline C(11) & 570 & 1061 & 813 & 247 & 816 & 381 \\
\hline $\mathrm{O}(12)$ & 1097 & 1345 & 896 & 34 & 1185 & -11 \\
\hline$O(13)$ & 871 & 1417 & 977 & -243 & 320 & 180 \\
\hline $\mathrm{N}(14)$ & 821 & 946 & 482 & -205 & 806 & $-\mathbf{3 2 0}$ \\
\hline$C(15)$ & 517 & 964 & 500 & 124 & 610 & $\mathbf{3 6 8}$ \\
\hline$O(16)$ & 900 & 1140 & 690 & 107 & 1179 & 138 \\
\hline$O(17)$ & 553 & 1129 & 744 & 11 & 845 & 128 \\
\hline$O(18)$ & 1352 & 1046 & 962 & -184 & 1884 & -128 \\
\hline C(19) & 572 & 990 & 740 & -128 & 760 & -154 \\
\hline$C(20)$ & 962 & 1261 & 817 & 150 & 1133 & 235 \\
\hline$C(21)$ & 687 & 1835 & 872 & 9 & 780 & -37 \\
\hline $\mathrm{C}(22)$ & 487 & 1834 & 798 & 108 & 723 & 7 \\
\hline$C(23)$ & 729 & 1648 & 783 & 773 & 942 & 137 \\
\hline $\mathrm{C}(24)$ & 690 & 1311 & 707 & 172 & 829 & \\
\hline
\end{tabular}




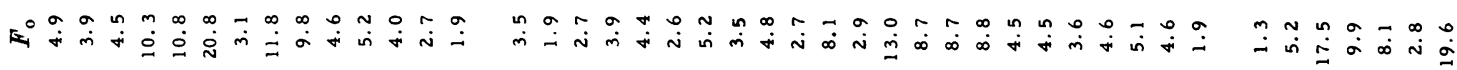

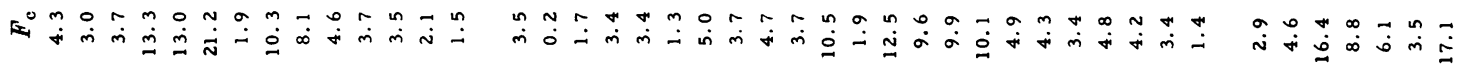

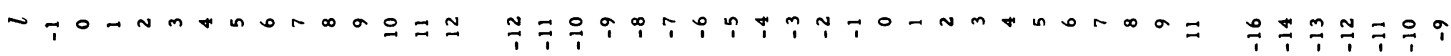

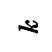

o

re

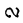

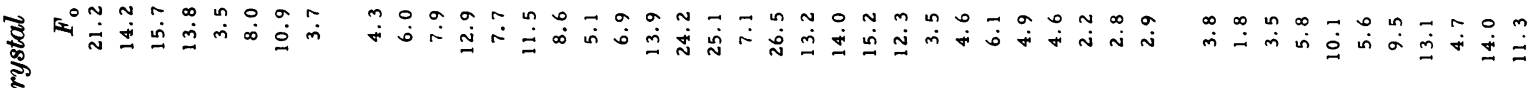

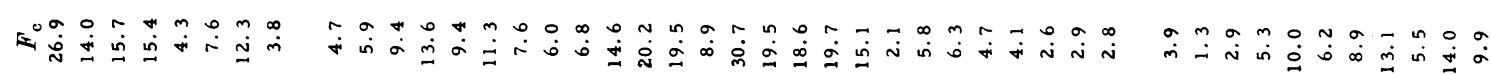

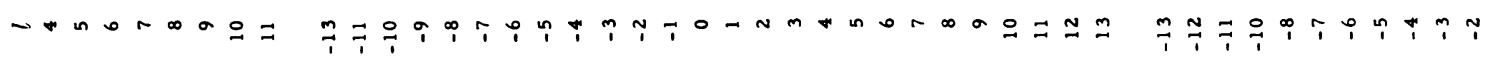

เ

$\sim$

se

E है

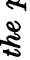

\$े

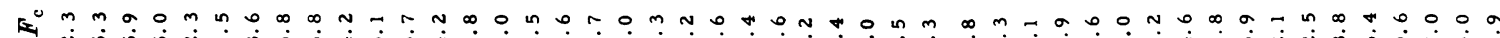

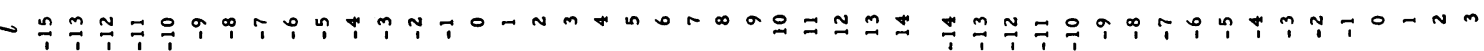
$2 \rightarrow$

$m$

다

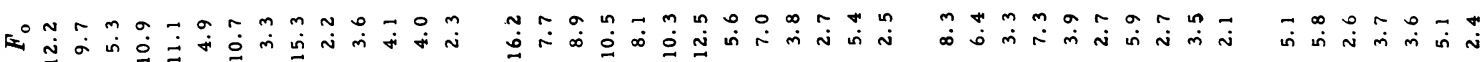
క్రి

\%

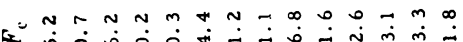

H- $-\infty \sim \sigma \infty \infty-\infty \sim N 0$

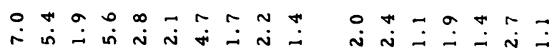

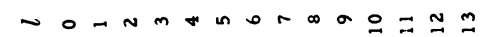

$0-n m+\ln 0+\infty a 0=\pi$

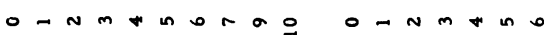

$\$ 6$

$\rightarrow 0$

$\infty$

우

$\Im$

○

○

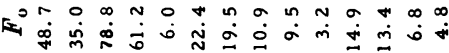

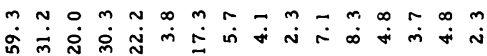

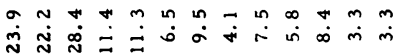

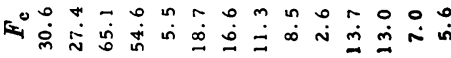

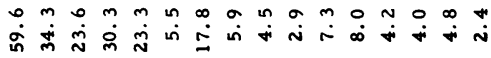

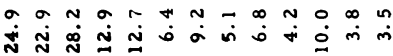

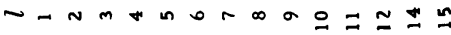

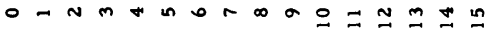

$\approx 0$

o

$\sim 0$

$\circ$

- $-N-\ln 0+\infty a=N \pm$ 


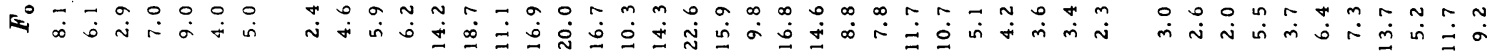

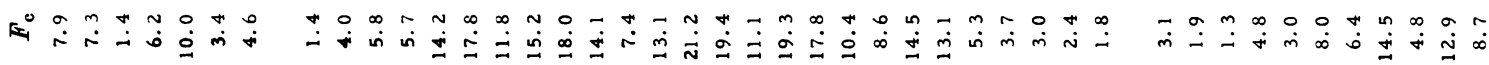

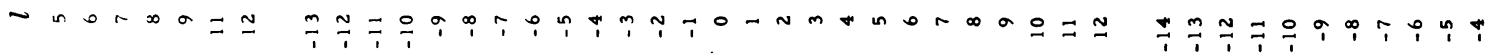

2 is

ne

2

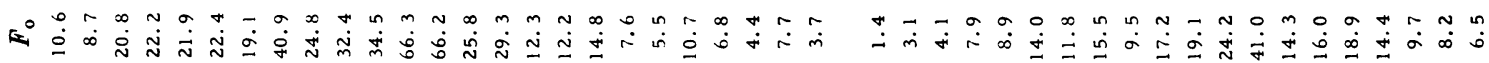

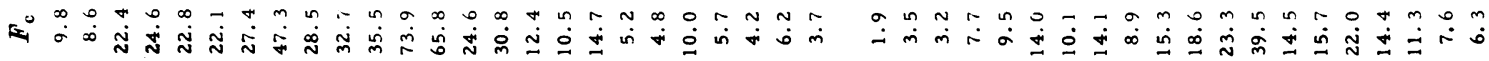

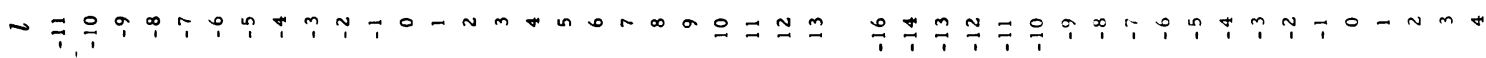

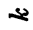

se

m

ع

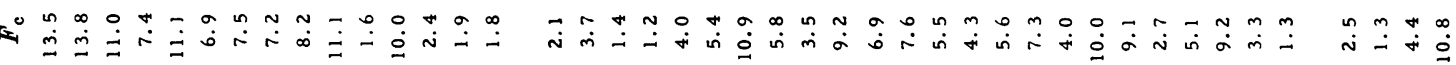
$\sim \quad m \sim T 0-n m$ m $\infty$ $\infty$ $-1$ o

n

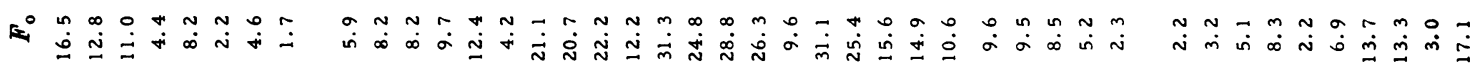

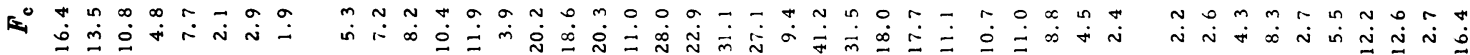

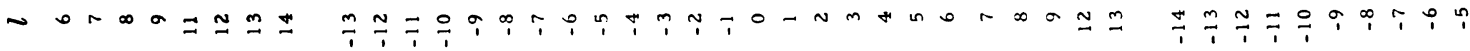

$\approx$ 4 $\omega$

N o

$\sim$

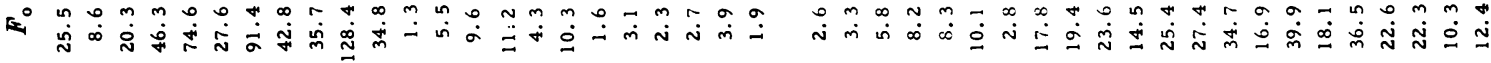

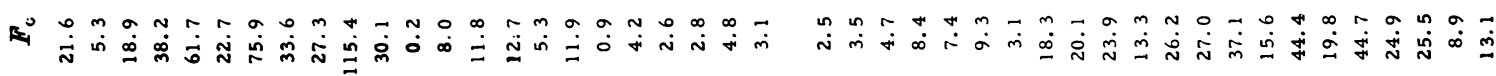
$\leqslant$ 


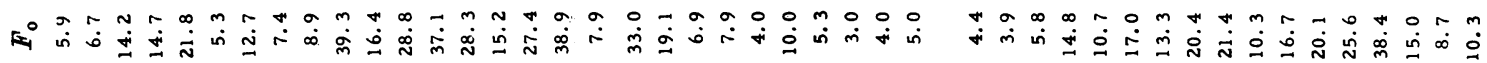

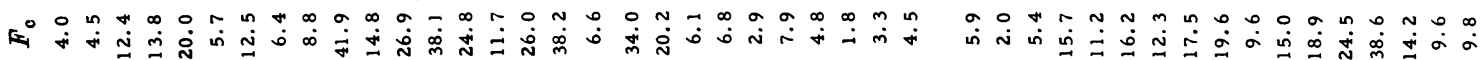

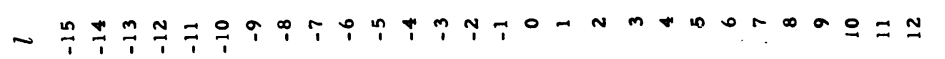

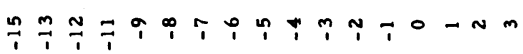

$+r$

m

te 10

๘

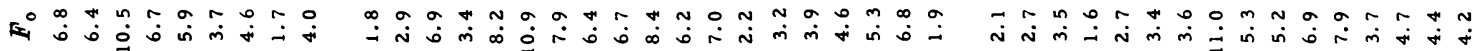

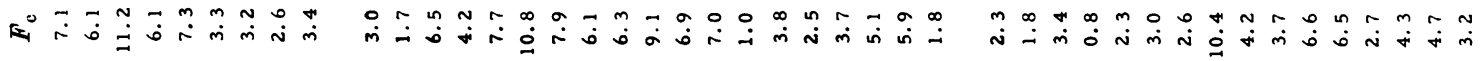

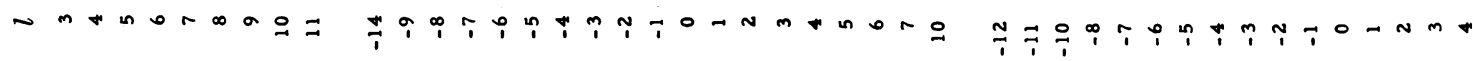

$2 \infty \infty$

a H

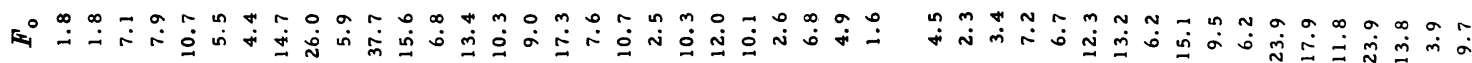

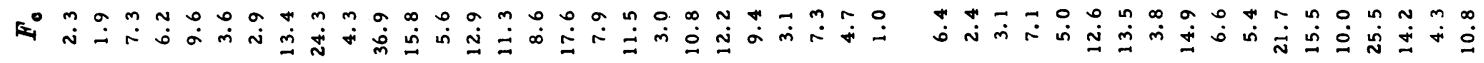

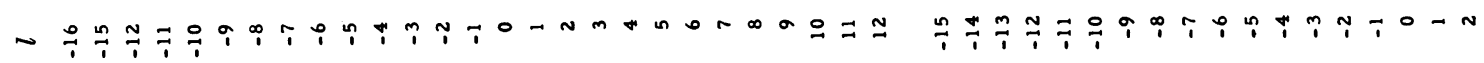

$2+$

$\sim 4$

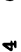

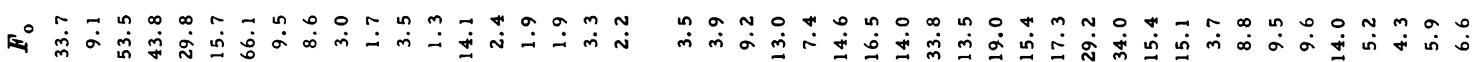

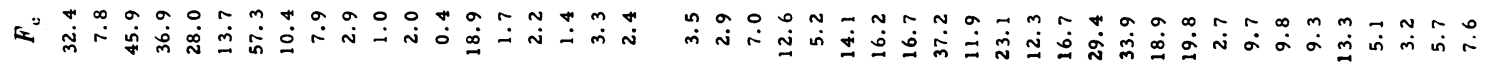

-

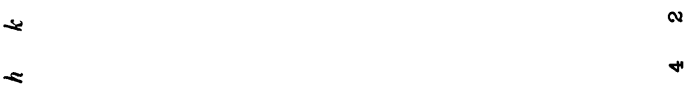

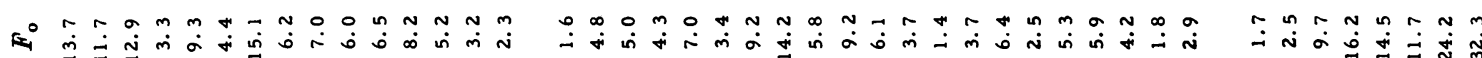

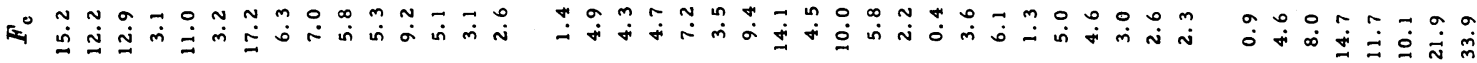

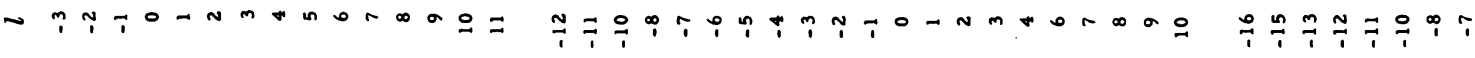


$\varepsilon$ 迸

E

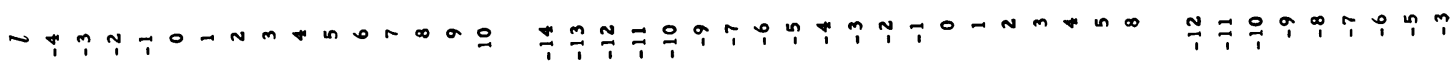
$\begin{array}{lll}0 & \infty & 0 \\ & \infty & 0\end{array}$

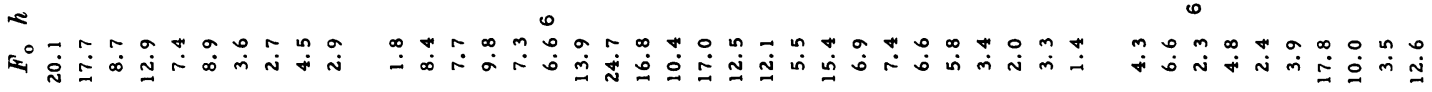

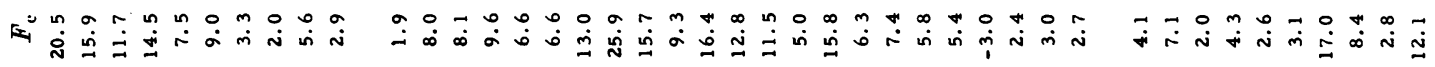
น-normeno

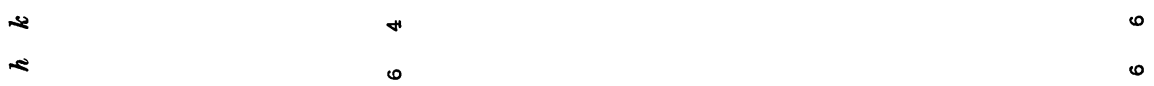

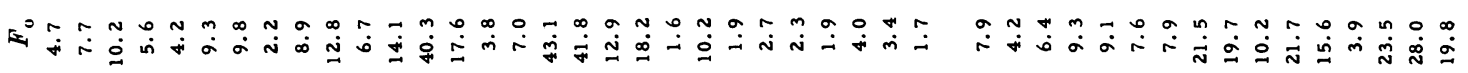

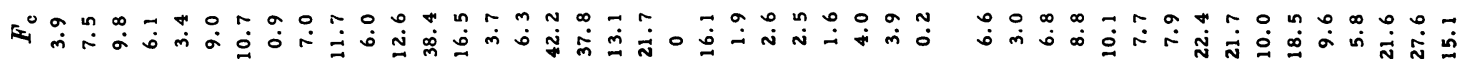

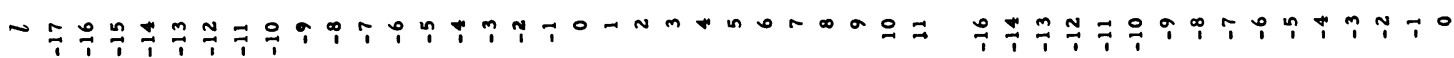
$\approx 0$

50

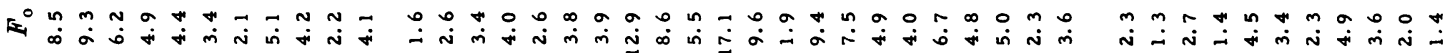

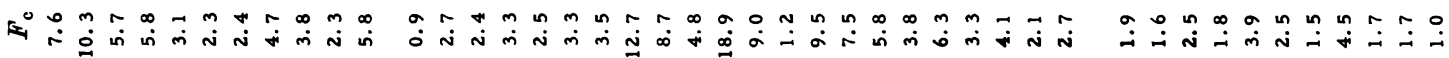
- TO-nm+nor\& 0 न

S 2 क

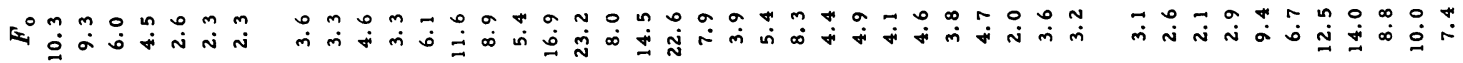

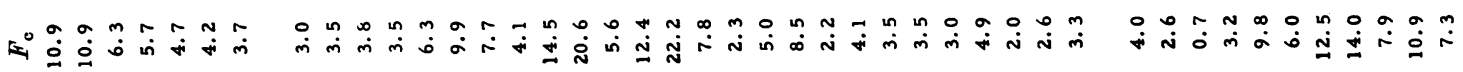
- n $+\infty$ is

- n 2 


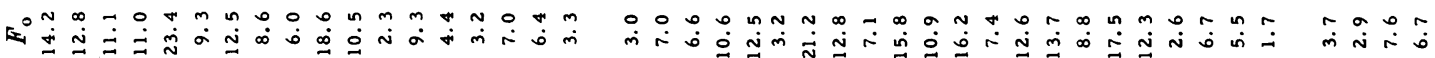

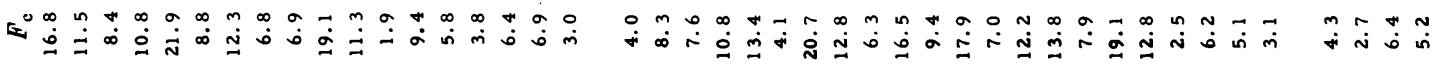

-

$\leftarrow$

$\sim$

$\infty$

$\infty$

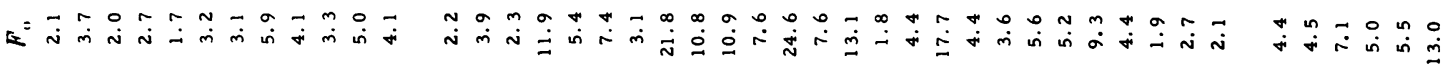

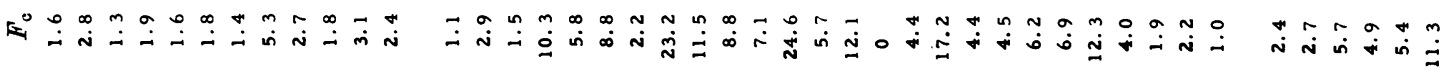

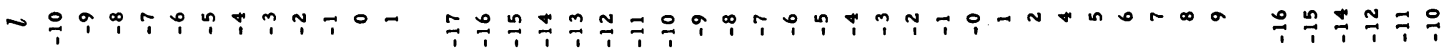

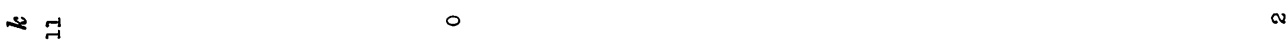

*

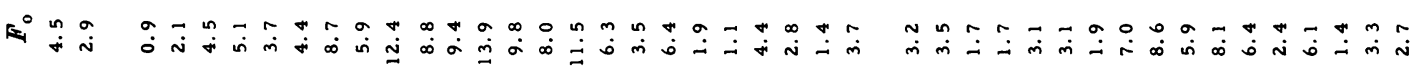

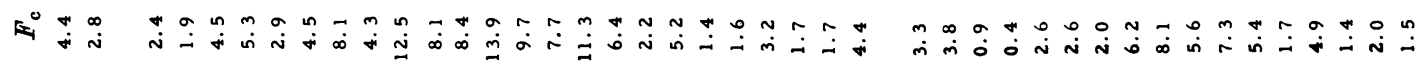
L

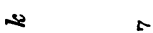

$\sim 2$ $\infty$

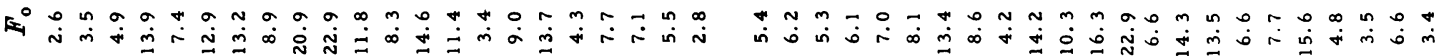

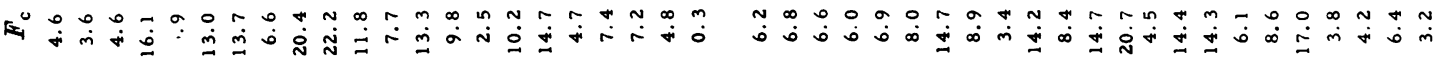

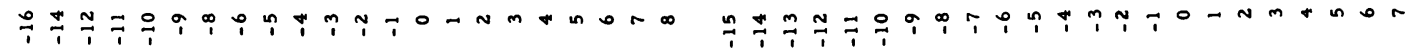
s o

เง

2 r

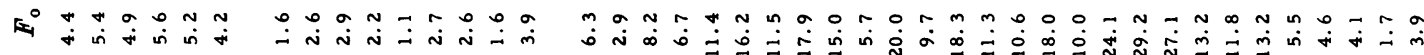
Ei se ๙ r 


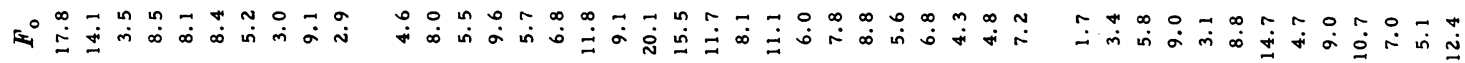

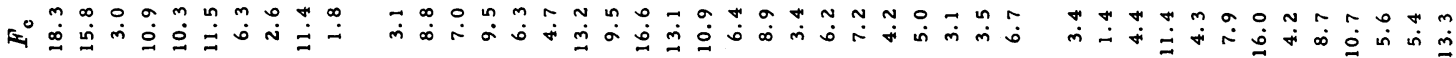

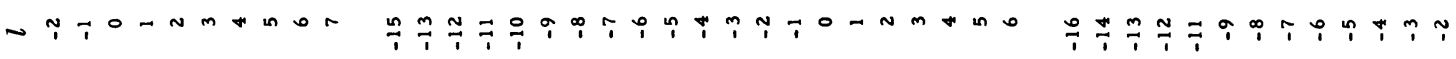

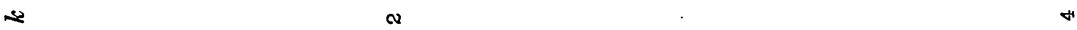
-

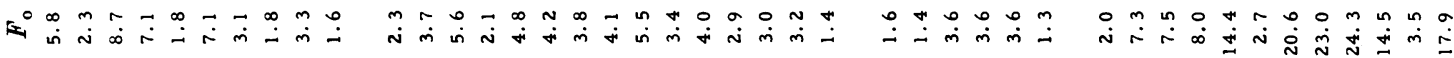

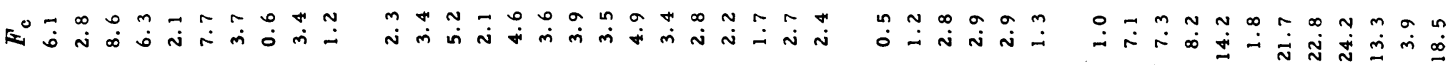

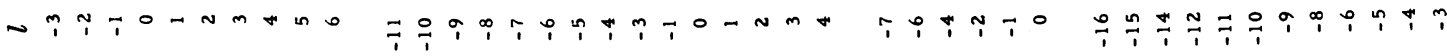
se
c)
A
e
a
o 우

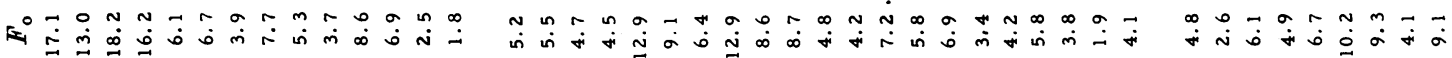

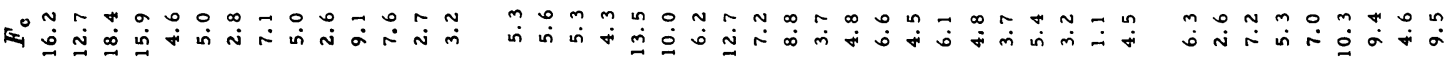
s

나

os

o

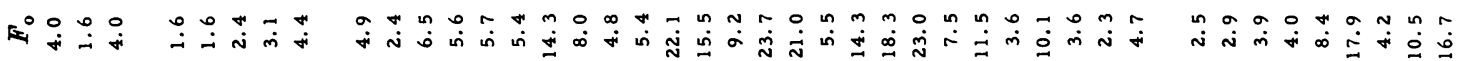

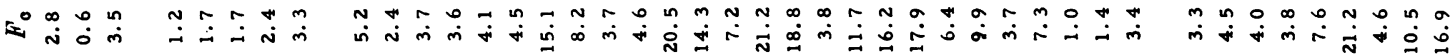

- - Nm i

\begin{tabular}{|c|}
\hline 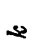 \\
\hline
\end{tabular}

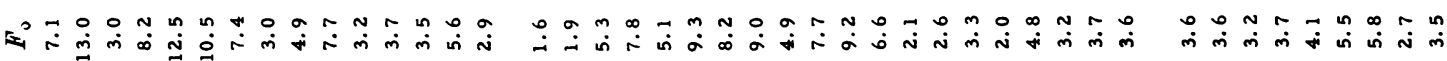

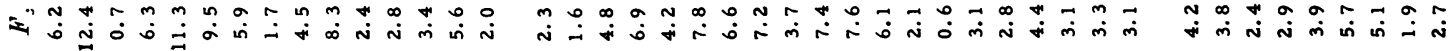
น $\begin{array}{lll}\infty & \infty & \infty\end{array}$ 


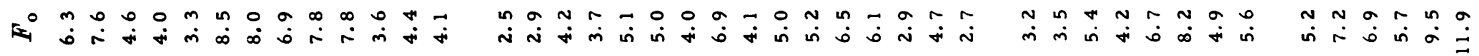

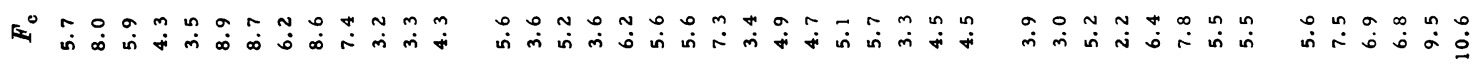

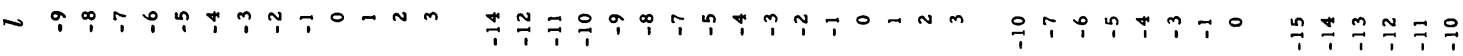

s

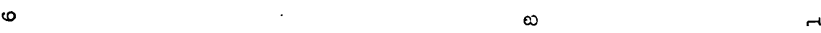

Ne

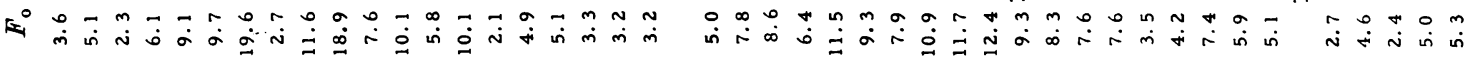

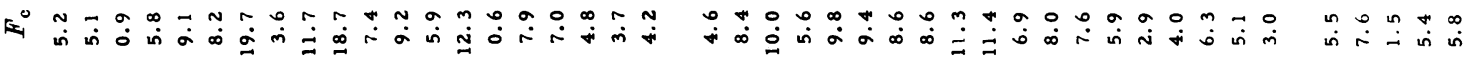

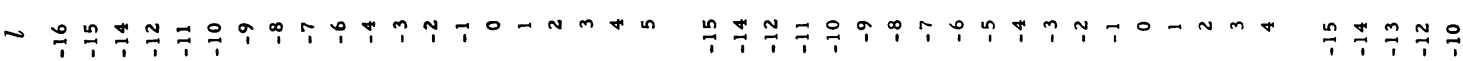

$\$ 0$

Ne

I

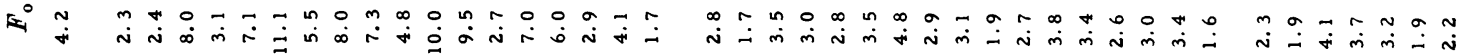

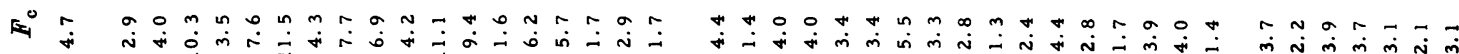

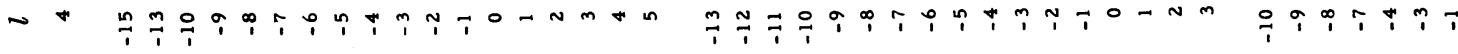
s 20 ate $\quad$ H

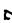
の

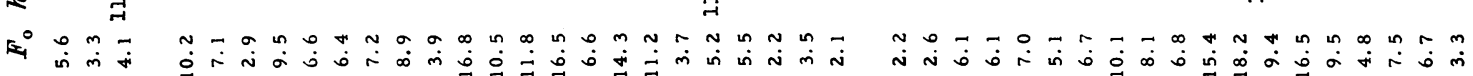

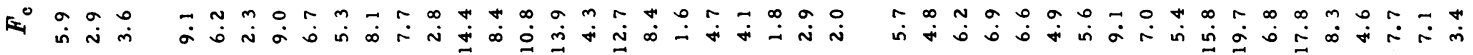

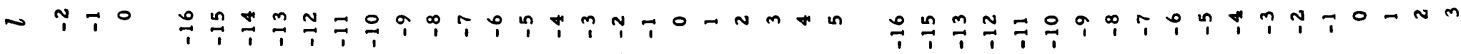
S $\rightarrow 2 M$

Ne $\quad$ H

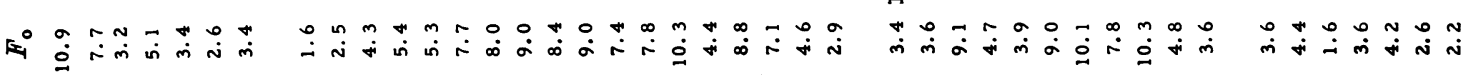

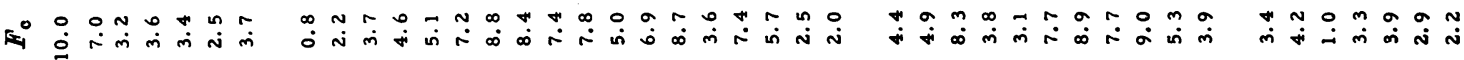

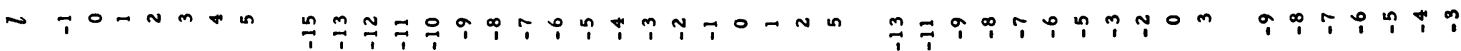
$+$ 0

$\infty$ 웅

No 우 $\circ$ 
Table 3 (continued)

\begin{tabular}{|c|c|c|c|c|c|c|c|c|c|c|c|c|c|c|}
\hline \multirow[t]{14}{*}{$h$} & $k$ & $l$ & $F_{\mathrm{c}}$ & $F_{\mathrm{o}}$ & $h$ & $k$ & $l$ & $F_{\mathrm{c}}$ & $F_{0}$ & $h$ & $k$ & $l$ & $F_{\mathrm{c}}$ & $F_{\mathrm{o}}$ \\
\hline & & -9 & 6.8 & 7.6 & & & -7 & 4.5 & 3.5 & 14 & 6 & -11 & 2.1 & 1.6 \\
\hline & & -8 & 9.5 & 11.8 & & & -6 & 2.3 & 3.0 & & & -10 & 5.0 & 3.7 \\
\hline & & -7 & 1.5 & 3.5 & & & -5 & 4.9 & 3.6 & & & -9 & 8.4 & 6.1 \\
\hline & & -6 & 6.5 & 9.5 & & & -4 & 2.4 & 1.6 & & & -7 & 4.9 & 3.0 \\
\hline & & -5 & 11.4 & 14.8 & & & -5 & 3.2 & 3.1 & & & -6 & 9.5 & 7.0 \\
\hline & & -3 & 7.7 & 9.9 & & & -2 & 4.0 & 3.1 & & & -4 & 6.3 & 4.4 \\
\hline & & -2 & 4.3 & 6.1 & & & -1 & 2.9 & 1.1 & & & -3 & 3.7 & 3.1 \\
\hline & & -1 & 7.3 & 9.2 & & & & & & & & & & \\
\hline & & 0 & 8.0 & 9.4 & 14 & 0 & -14 & 2.5 & 2.9 & 15 & 1 & -13 & 3.3 & 2.6 \\
\hline & & 1 & 2.5 & 3.9 & & & -13 & 2.7 & 2.7 & & & -12 & 7.5 & 7.3 \\
\hline & & 2 & 5.0 & 7.2 & & & -12 & 9.1 & 6.7 & & & -11 & 11.2 & 10.6 \\
\hline & & 3 & 4.8 & 5.4 & & & -11 & 2.5 & 2.9 & & & -10 & 6.2 & 6.6 \\
\hline & & & & & & & -10 & 7.8 & 5.8 & & & -9 & 5.5 & 7.5 \\
\hline \multirow[t]{14}{*}{13} & 3 & -14 & 8.7 & 4.8 & & & -9 & 2.4 & 3.0 & & & -8 & 13.6 & 14.2 \\
\hline & & -13 & 5.7 & 3.6 & & & -8 & 7.8 & 6.9 & & & -7 & 3.1 & 3.7 \\
\hline & & -12 & 6.5 & 4.6 & & & -6 & 2.0 & 2.3 & & & -6 & 3.7 & 4.7 \\
\hline & & -11 & 11.5 & 8.2 & & & -5 & 2.5 & 2.9 & & & -5 & 12.1 & 12.8 \\
\hline & & -10 & 8.1 & 7.5 & & & -3 & 1.7 & 2.2 & & & -4 & 2.5 & 2.9 \\
\hline & & -9 & 7.1 & 6.7 & & & -1 & 4.3 & 4.4 & & & -3 & 5.6 & 4.2 \\
\hline & & -7 & 7.9 & 7.5 & & & 0 & 3.5 & 3.1 & & & -2 & 5.1 & 5.1 \\
\hline & & -6 & 4.1 & 4.1 & & & 1 & 2.9 & 2.1 & & & -1 & 39 & 4.1 \\
\hline & & -5 & 8.0 & 6.9 & & & & & & & & & & \\
\hline & & -4 & 5.7 & 4.8 & 14 & 2 & -13 & 5.5 & 4.2 & 15 & 3 & -12 & 5.0 & 2.1 \\
\hline & & -3 & 7.4 & 7.1 & & & -12 & 7.0 & 7.0 & & & -11 & 6.5 & 3.4 \\
\hline & & -2 & 8.2 & 7.7 & & & -11 & 3.7 & 5.5 & & & -9 & 8.0 & 5.7 \\
\hline & & 1 & 5.2 & 4.8 & & & -10 & 11.1 & 9.6 & & & -8 & 6.6 & 5.1 \\
\hline & & & & & & & -9 & 5.6 & 7.1 & & & -7 & 0.9 & 3.0 \\
\hline \multirow[t]{15}{*}{13} & 5 & -13 & 4.2 & 2.7 & & & -7 & 7.1 & 8.2 & & & -6 & 6.5 & 5.1 \\
\hline & & -12 & 2.3 & 2.2 & & & -6 & 6.3 & 8.6 & & & -5 & 5.1 & 2.9 \\
\hline & & -11 & 6.8 & 4.9 & & & -5 & 3.7 & 4.1 & & & & & \\
\hline & & -10 & 6.2 & 5. 1 & & & -4 & 5.9 & 5.6 & 15 & 5 & -10 & 4.2 & 2.0 \\
\hline & & -9 & 5.2 & 3.3 & & & -3 & 5.9 & 6.1 & & & -8 & 5.6 & 3.6 \\
\hline & & -8 & 3.8 & 3.3 & & & -2 & 4.4 & 3.9 & & & -7 & 4.7 & 3.2 \\
\hline & & -7 & 6.7 & 6.8 & & & -1 & 5.4 & 6.6 & & & -6 & 5.0 & 3.4 \\
\hline & & -5 & 4.3 & 2.6 & & & 0 & 4.5 & 4.7 & & & -5 & 4.3 & 2.7 \\
\hline & & -4 & $5: 9$ & 5.6 & & & 1 & 1.7 & 2.8 & & & -4 & 1.5 & 2. 1 \\
\hline & & -3 & 6.8 & 5.6 & & & & & & & & & & \\
\hline & & -2 & 5.9 & 5.1 & 14 & 4 & -13 & 9.2 & 4.0 & 16 & 0 & -10 & 5.2 & 3.9 \\
\hline & & -1 & 3.7 & 4.2 & & & -12 & 8.0 & 4.4 & & & -8 & 2.3 & 1.6 \\
\hline & & 0 & 6.8 & 5.5 & & & -10 & 8.8 & 5.5 & & & -7 & 4.3 & 3.4 \\
\hline & & 1 & 4.9 & 5.3 & & & -9 & 9.5 & 6.0 & & & -5 & 2.6 & 2.3 \\
\hline & & & & & & & -7 & 7.4 & 5.6 & & & -4 & 8.4 & 5.6 \\
\hline \multirow[t]{4}{*}{13} & 7 & -11 & 4.4 & 2.6 & & & -6 & 9.3 & 6.8 & & & & & \\
\hline & & -10 & 3.1 & 2.3 & & & -4 & 7.4 & 5.7 & 16 & 2 & -10 & 8.2 & 5.4 \\
\hline & & -9 & 3.3 & 2.7 & & & -3 & 2.6 & 3.5 & & & -8 & 3.9 & 4.4 \\
\hline & & -8 & 7.1 & 4.2 & & & -2 & 5.8 & 4.8 & & & -7 & 5.3 & 4.5 \\
\hline
\end{tabular}

non-polar layers are drawn in Fig. 8, which shows the contact distances less than $4 \AA$ between atoms in this region. There is an additional contact, not included in Fig. 8, of $3.78 \AA$ between the methyl group, $\mathrm{CH}_{3}(10)$, and the phenoxy $\mathrm{CH}(24)$ of the molecule after one unit-cell repeat along $b$. The polar layers are shown in Fig. 9. Here the molecules are linked in chains by hydrogen bonds running parallel with the $b$ axis, between the amide oxygen, $\mathrm{O}(16)$ and carboxyl oxygen, $\mathrm{O}(12)$. The $\mathrm{O}(16)-\mathrm{O}(12)$ distance is $2 \cdot 76 \AA$ and the angle $\mathrm{C}(11)-\mathrm{O}(12) \cdots \mathrm{O}(16)$ is $126^{\circ}$. It is clear that $\mathrm{O}(12)$ should be the hydroxyl oxygen of the carboxyl group; in agreement with this, $\mathrm{C}(11)-\mathrm{O}(12)$ is $1.35 \AA$ and $\mathrm{C}(11)-\mathrm{O}(13) 1.21 \AA$. Within each molecule there is a short contact distance of $2.83 \AA$ between $\mathrm{O}(13)$ and $N(4)$. There are no short hydrogen-bonded contacts across the polar layers.

The appearance of the phenoxymethylpenicillin molecule as a whole is shown in Fig. 10. It differs from the benzylpenicillin ion in several features, both in individual bond lengths and in details of the molecular conformation. The two molecules are directly compared in Figs. 11 and 12 which show 
Table 4. Bond lengths and angles of the phenoxymethylpenicillin molecule

\begin{tabular}{|c|c|}
\hline \multicolumn{2}{|c|}{ Bond length $(\AA)^{*}$} \\
\hline $\mathrm{S}(1)-\mathrm{C}(2)$ & $1 \cdot 87$ \\
\hline $\mathrm{S}(1)-\mathrm{C}(5)$ & $1 \cdot 82$ \\
\hline$C(2)-C(3)$ & 1.57 \\
\hline $\mathrm{C}(2)-\mathrm{C}(9)$ & \\
\hline$C(2)-C(10)$ & 1.58 \\
\hline$C(3)-C(11)$ & 1.54 \\
\hline $\mathrm{C}(3)-\mathrm{N}(4)$ & $1 \cdot 4$ \\
\hline $\mathrm{N}(4)-\mathrm{C}(5)$ & 1.52 \\
\hline $\mathrm{N}(4)-C(7)$ & $1 \cdot 46$ \\
\hline$C(5)-C(6)$ & 1.58 \\
\hline$C(6)-C(7)$ & 1.55 \\
\hline$C(6)-N(14)$ & $1 \cdot 44$ \\
\hline$C(7)-O(8)$ & $1 \cdot 21$ \\
\hline $\mathrm{C}(11)-\mathrm{O}(12$ & $1 \cdot 35$ \\
\hline $\mathrm{C}(11)-\mathrm{O}(1$ & $1 \cdot 2$ \\
\hline $\mathrm{N}(14)-\mathrm{C}(15$ & $1 \cdot 37$ \\
\hline $\mathrm{C}(15)-\mathrm{O}(16$ & $1 \cdot 29$ \\
\hline$C(15)-C(17)$ & $1 \cdot 4$ \\
\hline $\mathrm{C}(17)-\mathrm{O}(18)$ & $1 \cdot 47$ \\
\hline $\mathrm{O}(18)-\mathrm{C}(19$ & $1 \cdot 40$ \\
\hline$C(19)-C(20)$ & 1.42 \\
\hline$C(19)-C(24)$ & $\mathbf{1} \cdot \mathbf{4}$ \\
\hline$C(20)-C(21)$ & $1 \cdot 4$ \\
\hline $\mathrm{C}(21)-\mathrm{C}(22)$ & $1 \cdot 3$ \\
\hline $\mathrm{C}(22)-\mathrm{C}(2$ & \\
\hline $\mathrm{C}(23)-\mathrm{C}($ & \\
\hline
\end{tabular}

\begin{tabular}{|c|c|}
\hline \multicolumn{2}{|l|}{ Bond angle } \\
\hline$C(2)-S(1)-C(5)$ & $96^{\circ}$ \\
\hline $\mathrm{S}(1)-\mathrm{C}(2)-\mathrm{C}(3)$ & 105 \\
\hline $\mathrm{S}(1)-\mathrm{C}(2)-\mathrm{C}(10)$ & 108 \\
\hline $\mathrm{S}(1)-\mathrm{C}(2)-\mathrm{C}(9)$ & 109 \\
\hline $\mathrm{C}(3)-\mathrm{C}(2)-\mathrm{C}(10)$ & 113 \\
\hline $\mathrm{C}(3)-\mathrm{C}(2)-\mathrm{C}(9)$ & 110 \\
\hline $\mathrm{C}(9)-\mathrm{C}(2)-\mathrm{C}(10)$ & 112 \\
\hline $\mathrm{C}(2)-\mathrm{C}(3)-\mathrm{N}(4)$ & \\
\hline $\mathrm{C}(2)-\mathrm{C}(3)-\mathrm{C}(11)$ & 113 \\
\hline $\mathrm{N}(4)-\mathrm{C}(3)-\mathrm{C}(11)$ & 114 \\
\hline $\mathrm{C}(3)-\mathrm{N}(4)-\mathrm{C}(5)$ & \\
\hline $\mathrm{C}(3)-\mathrm{N}(4)-\mathrm{C}(7)$ & 129 \\
\hline $\mathrm{C}(5)-\mathrm{N}(4)-\mathrm{C}(7)$ & \\
\hline $\mathrm{S}(1)-\mathrm{C}(5)-\mathrm{N}(4)$ & 103 \\
\hline$S(1)-C(5)-C(6)$ & 122 \\
\hline $\mathrm{N}(4)-\mathrm{C}(5)-\mathrm{C}(6)$ & 92 \\
\hline $\mathrm{C}(5)-\mathrm{C}(6)-\mathrm{C}(7)$ & 83 \\
\hline $\mathrm{C}(5)-\mathrm{C}(6)-\mathrm{N}(14)$ & 115 \\
\hline $\mathrm{C}(7)-\mathrm{C}(6)-\mathrm{N}(14)$ & 115 \\
\hline $\mathrm{C}(6)-\mathrm{C}(7)-\mathrm{N}(4)$ & 96 \\
\hline $\mathrm{C}(6)-\mathrm{C}(7)-0(8)$ & 136 \\
\hline $\mathrm{N}(4)-\mathrm{C}(7)-\mathrm{O}(8)$ & 128 \\
\hline $\mathrm{C}(3)-\mathrm{C}(11)-\mathrm{O}(12)$ & 115 \\
\hline $\mathrm{C}(3)-\mathrm{C}(11)-0(13)$ & 122 \\
\hline $\mathrm{O}(12)-\mathrm{C}(11)-\mathrm{O}(\mathbf{1 3})$ & 122 \\
\hline $\mathrm{C}(6)-\mathrm{N}(14)-\mathrm{C}(15)$ & 125 \\
\hline $\mathrm{O}(16)-\mathrm{C}(15)-\mathrm{C}(17)$ & \\
\hline$N(14)-C(15)-O(16)$ & \\
\hline $\mathbf{N}(\mathbf{1 4})-C(15)-C(17)$ & 120 \\
\hline $\mathrm{C}(15)-\mathrm{C}(17)-\mathrm{O}(18)$ & 106 \\
\hline$C(17)-O(18)-C(19)$ & \\
\hline$O(18)-C(19)-C(20)$ & 112 \\
\hline $\mathrm{O}(18)-\mathrm{C}(19)-\mathrm{C}(24)$ & 122 \\
\hline$C(20)-C(19)-C(24)$ & 126 \\
\hline $\mathrm{C}(19)-\mathrm{C}(20)-\mathrm{C}(21)$ & 115 \\
\hline $\mathrm{C}(20)-\mathrm{C}(21)-\mathrm{C}(22)$ & 121 \\
\hline $\mathrm{C}(21)-\mathrm{C}(22)-\mathrm{C}(23)$ & 123 \\
\hline $\mathrm{C}(22)-\mathrm{C}(23)-\mathrm{C}(24)$ & 121 \\
\hline $\mathrm{C}(23)-\mathrm{C}(\mathbf{2 4})-\mathrm{C}(19)$ & 114 \\
\hline
\end{tabular}

* The average C-C length is $1 \cdot 54_{5} \AA$; the average deviation from $1.54 \AA$ is $0.03 \AA$, and the maximum deviation $0.05 \AA$. In the benzene ring, the average $C_{a r}-C_{a r}$. length is $1 \cdot 41_{3} \AA$; the average deviation from $1 \cdot 39 \AA$ is $0 \cdot 035 \AA$, and the maximum deviation $0 \cdot 06 \AA$.

projections of the observed atomic positions on two planes, the first defined by the $\beta$-lactam amide group in each molecule, the second by the amide side chain.

In the more rigid parts of the two molecules, the thiazolidine and $\beta$-lactam rings, the general configuration and many of the bond lengths are very similar. Four of the atoms of the thiazolidine ring in phenoxymethylpenicillin lie at distances $0 \cdot 04 \AA$ or less from a single plane; the fifth, $C(3)$, deviates by $0.51 \AA$ (Table 5). The atoms of the $\beta$-lactam ring are also within $0 \cdot 04 \AA$ of a single plane, from which $\mathrm{O}(8)$ deviates, as in benzylpenicillin, by $0.15 \AA$ (cf. Pitt, 1952). However, the $\mathrm{C}(7)-\mathrm{N}(4)$ distance in the $\beta$-lactam ring is longer in phenoxymethylpenicillin than in benzylpenicillin, $1.46 \AA$ compared with $1.35 \AA$, whereas the $\mathrm{C}(7)-\mathrm{O}(8)$ distance is a little shorter, $1 \cdot 21 \AA$ compared with $1 \cdot 24 \AA$. Owing to the uncertainties in the measurements, the differences are probably not as great as they now appear; as the figures stand, they suggest, as is very reasonable, that there is a greater contribution from normal amide resonance to the bond character in benzylpenicillin than in penicillin $\mathrm{V}$.

Other differences between the two molecules arise from small rotations about the different single bonds, particularly $\mathrm{C}(3)-\mathrm{C}(11), \mathrm{C}(6)-\mathrm{N}(14)$ and the bonds attaching the benzene rings. The most obvious effect of these rotations is to change the position of the benzene ring from one nearly parallel with the $\beta$-lactam-thiazolidine system in benzylpenicillin to one considerably inclined to these rings in phenoxymethylpenicillin. As Figs. 11 and 12 show, the plane of the benzene ring is nearly perpendicular to the plane of the amide side chain in the first case and nearly perpendicular to the plane of the $\beta$-lactam ring in the second. Such changes may, of course, be largely due to packing

Bioch. 1963, 86 
Table 5. Deviations of the atoms from the calculated least-square planes in the planar regions of the phenoxymethylpenicillin molecule

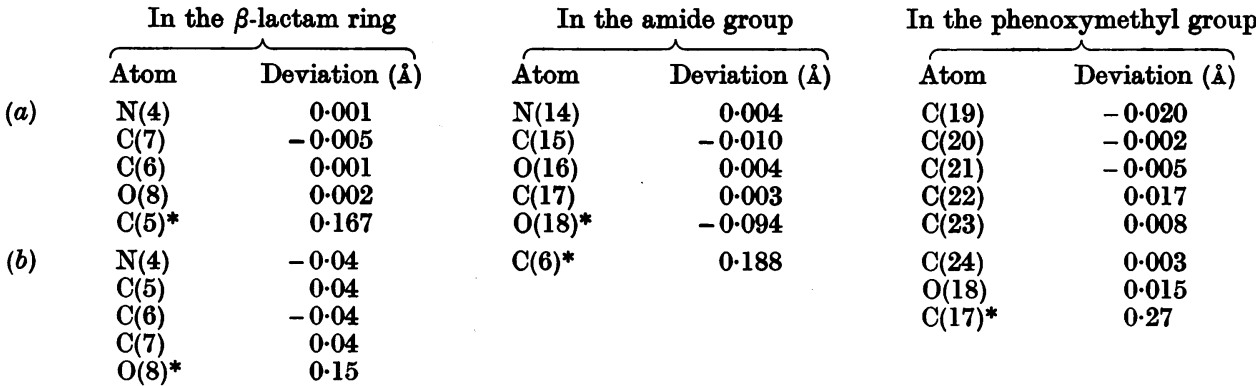

* These atoms were not included in the planes defined in the least-squares calculations.

(a) Plane of amide group. (b) Plane of ring.

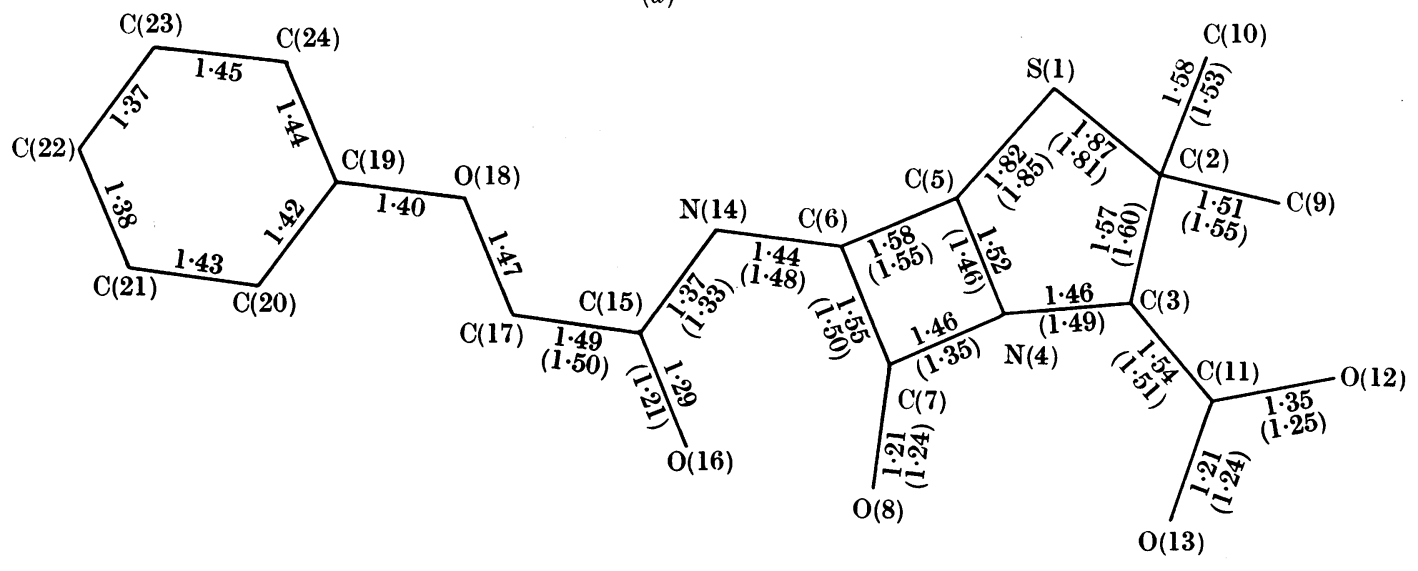

(b)

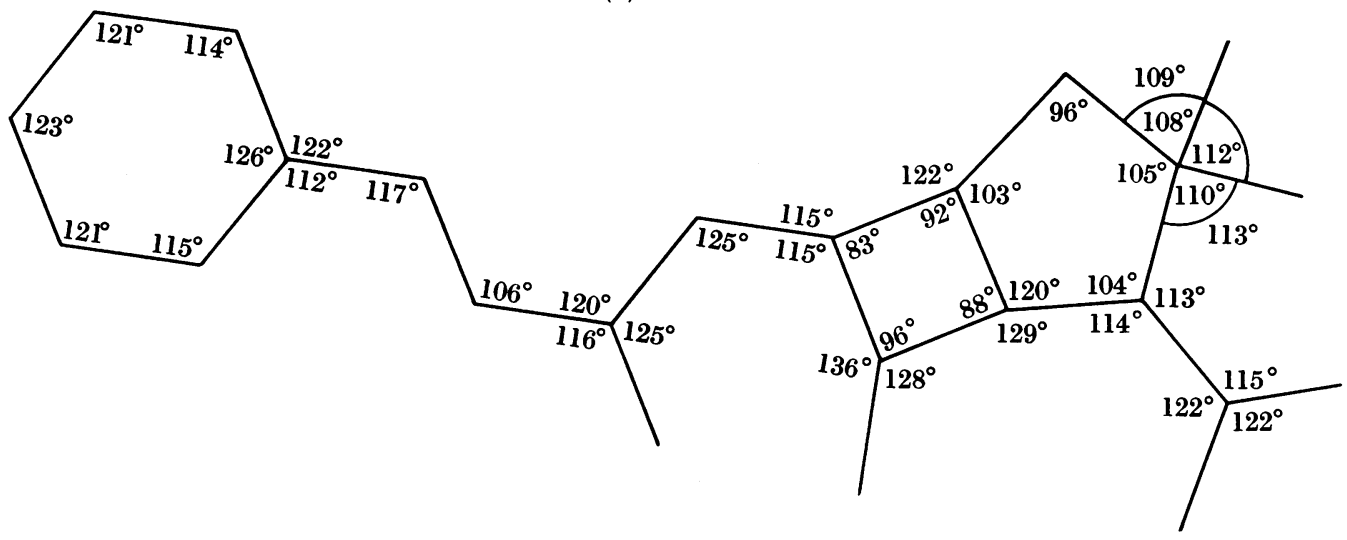

Fig. 6. (a) Numbering of the atoms in phenoxymethylpenicillin, together with the bond lengths found in the molecule compared with those in the benzylpenicillin ion (in parentheses) (J. S. Rollett \& A. Vaciago, personal communication). (b) Bond angles in phenoxymethylpenicillin. 
conditions within the crystal. The small rotation of the side chain around $\mathrm{C}(6)-\mathrm{N}(14)$ has, however, one effect that may be significant in relation to the molecular reactivity, that the $\mathrm{O}(8)-\mathrm{O}(16)$ distance is greater in penicillin $\mathrm{V}$ than in benzylpenicillin, $4 \cdot 2 \AA$ compared with $3 \cdot 8 \AA$.

The only region where it seems possible that an internal hydrogen bond exists in phenoxymethylpenicillin is between $\mathrm{O}(18)$ and $\mathrm{NH}(14)$. In both molecules, $O(18)$ lies very near to the plane of the amide group atoms $\mathrm{N}(14), \mathrm{C}(15), \mathrm{O}(16)$ and $\mathrm{C}(17)$. This position is one of those preferred on conformational grounds since it enables the hydrogen atoms of the $\mathrm{CH}_{2}$ group to stagger the $\mathrm{C}=\mathrm{O}$ bond. It brings both $\mathrm{N}(14)$ and the attached hydrogen atom, if this lies in the plane of the amide group, into close contact with $\mathrm{O}(\mathbf{1 8})$. But though the bond angle at $\mathrm{C}(17)$ is larger than tetrahedral in benzyl- penicillin, as if to stretch the contact distance, it is a little smaller than normal in phenoxymethylpenicillin. As a result, the contact distances observed are shorter in phenoxymethylpenicillin than in the benzylpenicillin ion; $\mathrm{N}(14)-\mathrm{O}(18)$ is $2.58 \AA$ and the corresponding estimated hydrogen contact distance is only $2 \cdot 10 \AA$. The situation in phenoxy methylpenicillin seems comparable with that found in many $\alpha$-amino acid structures where the amino group tends to lie in the plane of the carboxyl ion, as if some attraction existed between the nitrogen and oxygen atoms, whether due to their opposite charges or to the presence of hydrogen on the nitrogen atom. Here any hydrogen bond would necessarily be non-linear and very weak; the effect of the close contact between $\mathrm{NH}(14)$ and $\mathrm{O}(18)$ may still be sufficiently strong to influence the reactivity of the amide nitrogen atom

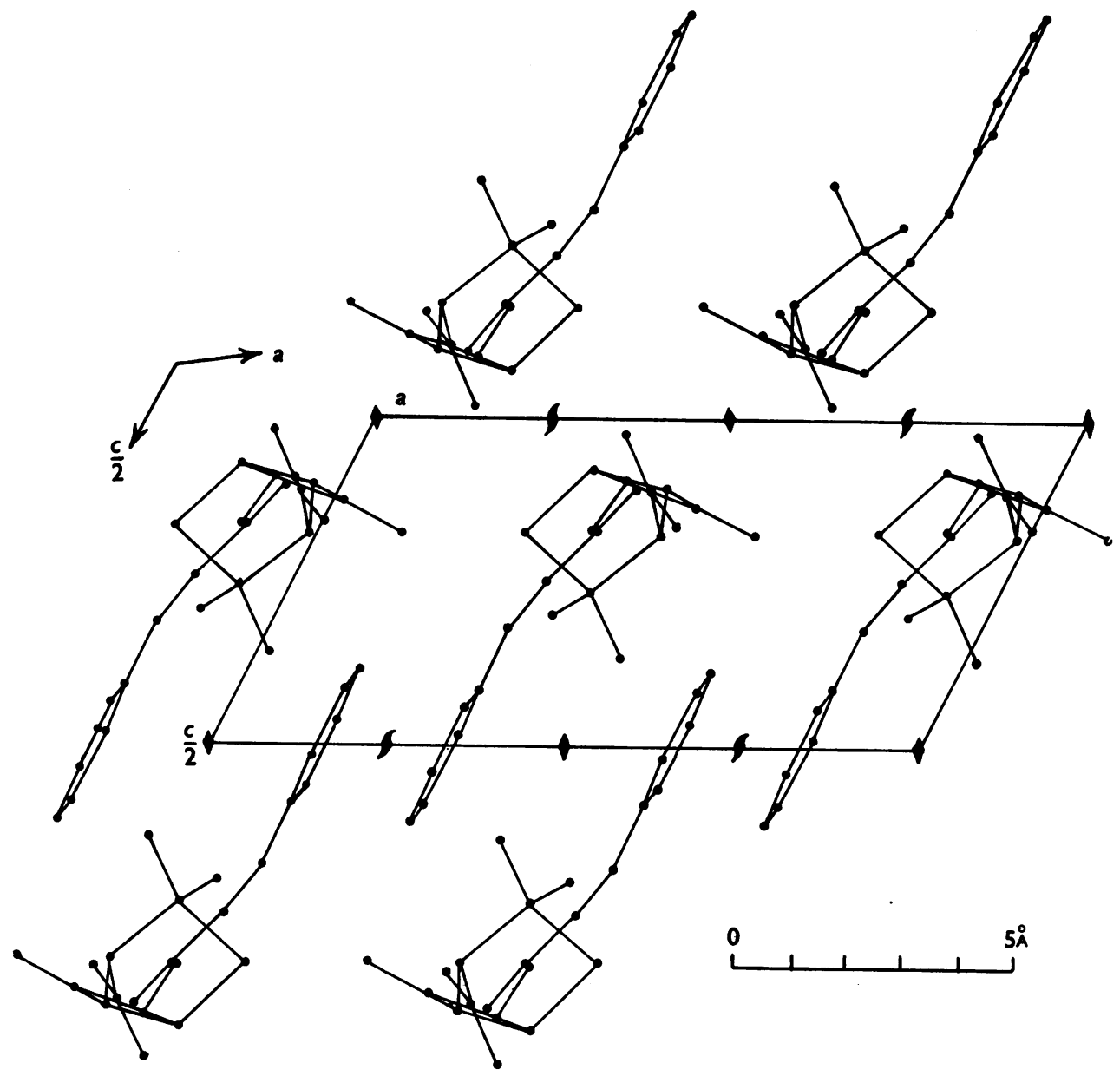

Fig. 7. Crystal structure of phenoxymethylpenicillin, seen projected along the $b$ axis. 


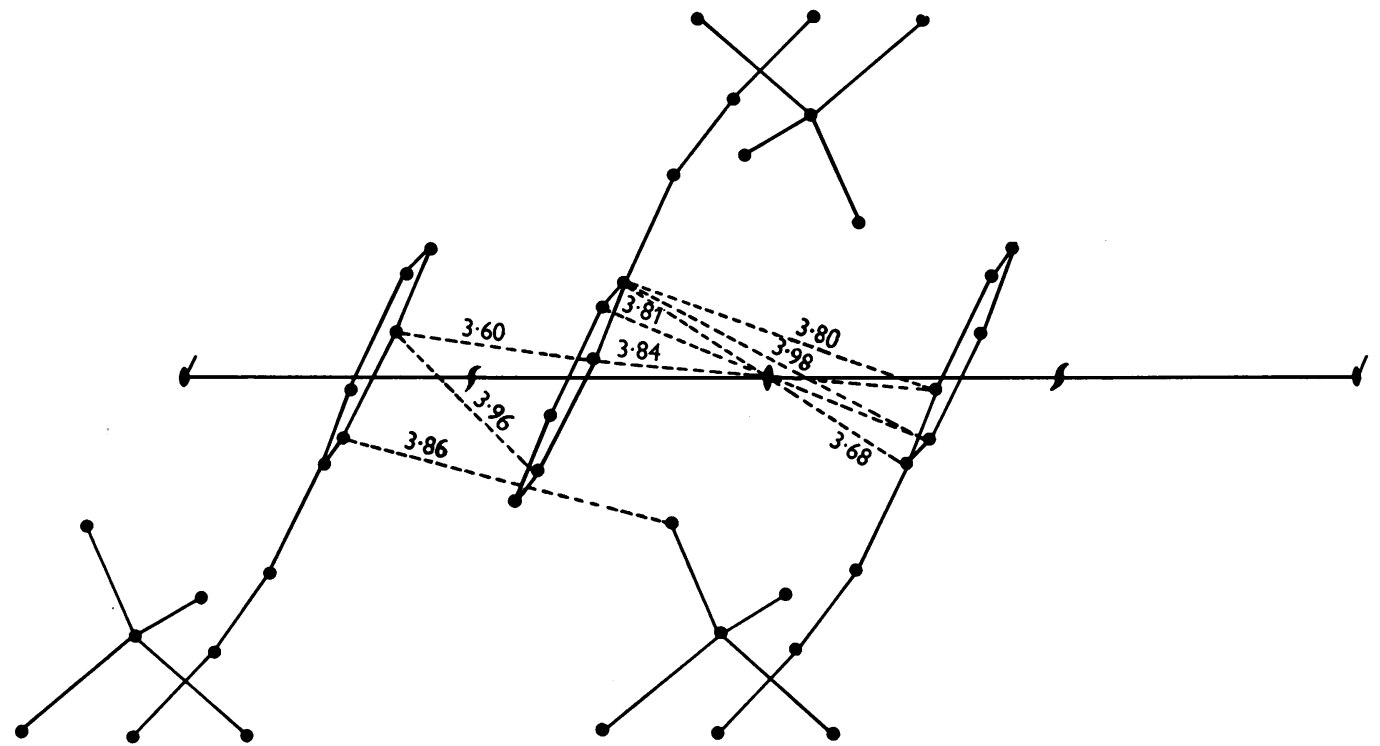

Fig. 8. Details of the non-polar contact layers in phenoxymethylpenicillin, seen projected along the $b$ axis.

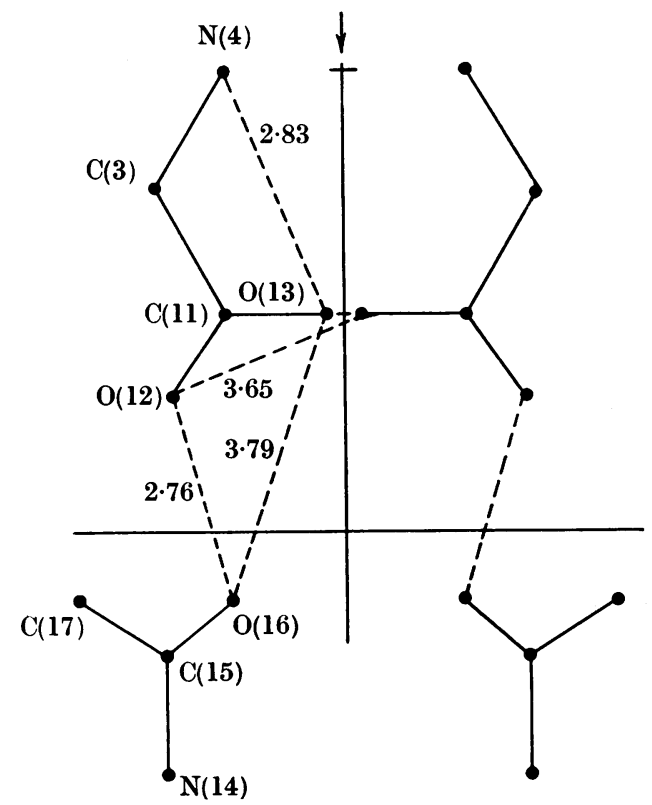

Fig. 9. Details of the polar layers in phenoxymethylpenicillin, seen projected along the $a$ axis.

and hence the stability of the molecule as a whole. A similar close contact must certainly occur in benzylpenicillin sulphone methyl ester, which was early discovered among penicillin derivatives to be remarkably stable to acid.
These results agree well, as far as they go, with the observations of Doyle, Nayler, Smith \& Store (1961) on new types of acid-stable penicillins. These authors correlate the stability towards acid of penicillins with the electron-repelling characteristics of the amide side-chain substituents. One might expect that such effects would show themselves in small differences in the interatomic distances in these molecules, and in details of molecular conformation of the kind observed in phenoxymethylpenicillin. Substituents such as chlorine or $\mathrm{NH}_{3}^{+}$at the $\alpha$-carbon atom of the benzyl group have the same distance relations as the phenoxymethyl oxygen atom to the side-chain amide atoms in the corresponding penicillin. It would be interesting to see whether they adopt similar arrangements in space.

\section{SUMMARY}

1. Crystals of phenoxymethylpenicillin were grown from acetone by the addition of water. They were found to be monoclinic, space group C2,

$$
\begin{array}{ll}
a=12 \cdot 7_{9} \pm 0 \cdot 02 \AA, & b=11 \cdot 23_{6} \pm 0 \cdot 007 \AA, \\
c=13 \cdot 3_{9} \pm 0 \cdot 02 \AA, & \beta=115^{\circ} 44^{\prime}, \quad Z=4 .
\end{array}
$$

2. The intensities of 1670 reflexions recorded on Weissenberg photographs were measured, partly visually, partly with a microdensitometer. Some difficulty was experienced from the deterioration of crystals during X-ray photography. 

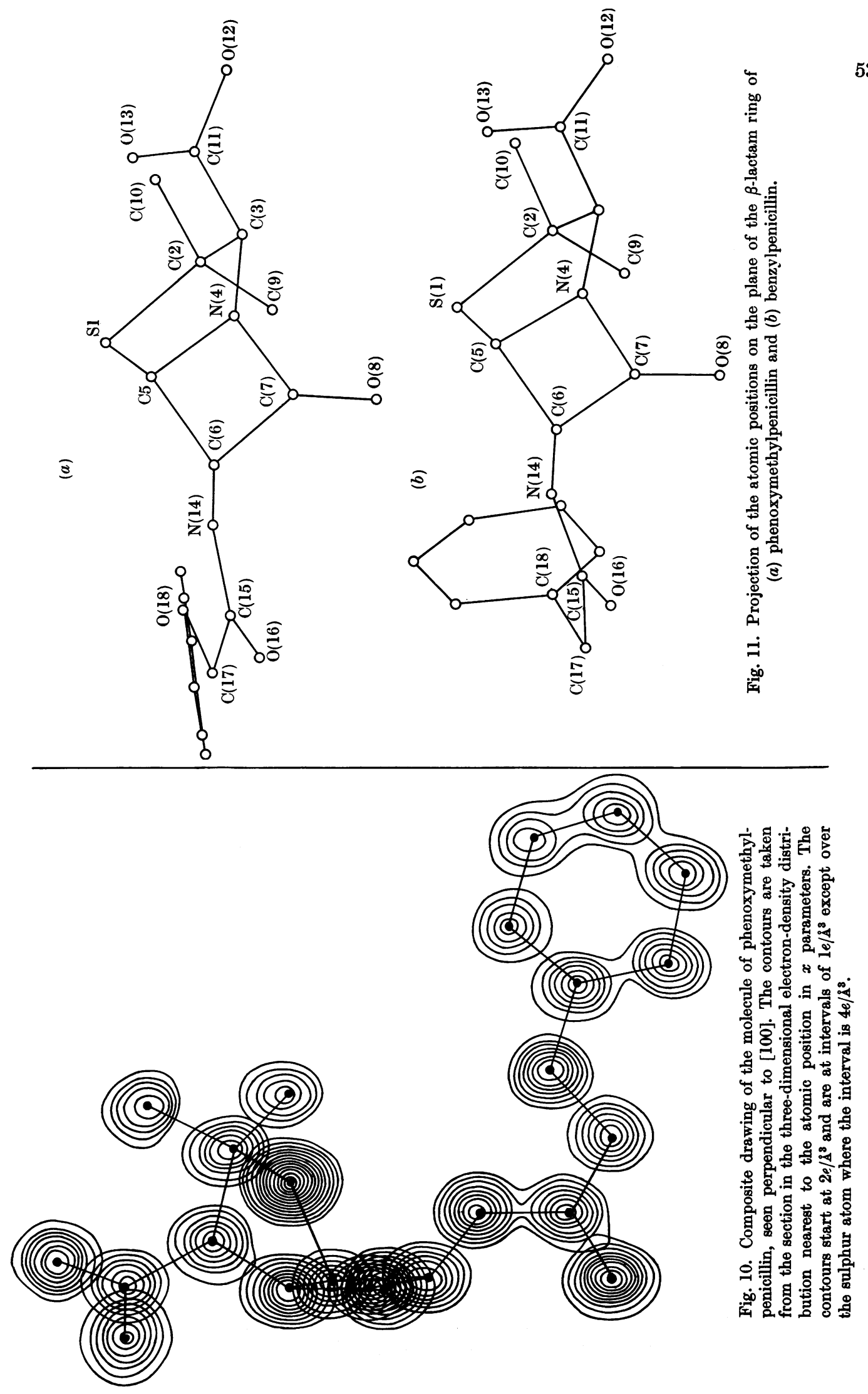
$(a)$.
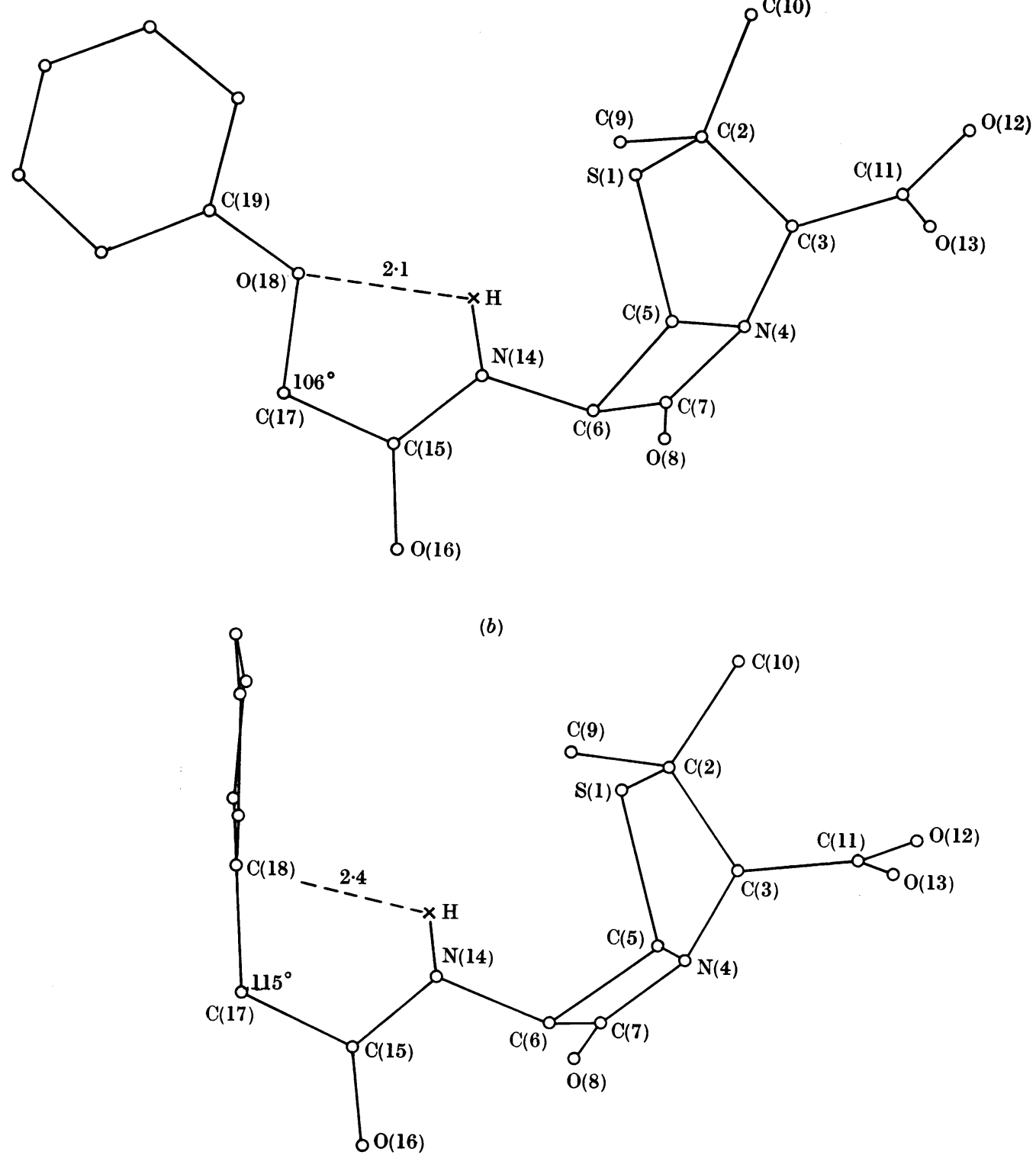

Fig. 12. Projection of the atomic positions on the plane of the amide side chain of $(a)$ phenoxymethylpenicillin and $(b)$ benzylpenicillin.

3. The structure was solved through the calculation of a three-dimensional Patterson synthesis, with coefficients modified to correspond to those from point atoms at rest. The S-S-vector peak was the highest observed. Other atomic positions were recognized by locating pairs of peaks in the Patterson distribution related by the $S-S$ vector. The only atomic position not so found was shown in a subsequent calculated three-dimensional electron-density distribution.

4. The structure was refined by a threedimensional anisotropic least-squares treatment. Though the $R$ value is now $12.6 \%$, the precision of atom placing does not seem very high. C-C distances deviated from expected values by an average of $0.03_{5} \AA$, maximum $0.06 \AA$. 
5. The molecule is present in the crystal structure as the free acid; hydrogen bonds between the amide oxygen atom and the carboxyl hydroxyl group link succeeding molecules in the direction of the $b$ axis. The thiazolidine- $\beta$-lactam nucleus is geometrically similar to that found in the benzylpenicillin salts; but rotations about single bonds change markedly the relative orientations of the benzene rings in the two molecules. There is a close contact, $2.58 \AA$, between the side-chain amide nitrogen atom and the oxygen of the phenoxymethyl group, which may indicate the presence of a very weak internal hydrogen bond in the molecule.

We thank Dr E. P. Abraham and Dr H. Margreiter for the samples of phenoxymethylpenicillin used and Dr J. S. Rollett for expert advice in all matters concerning computing and for the use of his Deuce and Mercury programmes. We are also indebted to Dr A. S. Vaciago for considerable help in the final stages of the analysis, to Dr M. M. Harding, Dr T. F. Lai, Dr O. S. Mills, Dr K. Prout and Dr R. Sparks for the use of Mercury programmes, and to Mrs M. Innes and Mr A. Westerdahl for technical assistance. A Rockefeller fellowship and a grant from the Swedish National Science Research Council to one of us (S. A.) are gratefully acknowledged. The investigation was supported in part by Research grant A-4006 (to S. A.) from the National Institute of Arthritis and Metabolic Diseases, U.S. Public Health Service.

\section{REFERENCES}

Abrahamsson, S. \& Maslen, E. N. (1960). Acta cryst., Camb., 13, 1001 .

Behrens, O. K., Corse, J. \& Edwards, J. P. (1948). J. biol. Chem. 175, 793.

Berghuis, J., Haanappel, M. I., Potters, M., Loopstra, B. O., MacGillavry, C. H. \& Veenendaal, A. L. (1955). Acta cryst., Camb., 8, 478.

Brandl, E. von \& Margreiter, H. (1954). Öst. Chem. Ztg, January, 55.

Crowfoot, D., Bunn, C. W., Rogers-Low, B. W. \& TurnerJones, A. (1949). The Chemistry of Penicillin, p. 310. Princeton: University Press.

Cruickshank, D. W. J. \& Robertson, A. P. (1953). Acta cryst., Camb., 6, 698.

Doyle, F. P., Nayler, J. H. C., Smith, H. \& Store, E. R. (1961). Nature, Lond., 191, 1091.

Hodgkin, D. \& Maslen, E. N. (1961). Biochem. J. 79, 393.

Hurdman, G. I. M. (1959). B.A. Thesis: University of Oxford.

Lipson, H. \& Cochran, W. (1953). The Determination of Crystal Structures, chapter 9. London: G. Bell and Sons Ltd.

Mills, O. S. \& Rollett, J. S. (1961). Computing Methods and the Phase Problem in X-Ray Crystal Analysis, p. 107. London: Pergamon Press Ltd.

Pitt, G. J. (1952). Acta cryst., Camb., 5, 770.

Viervoll, H. \& Ögrim, O. (1949). Acta cryst., Camb., 2, 277.

Biochem. J. (1963) 86, 535

\title{
A Partial Purification and some Properties of the Cytochrome Oxidase from Pig-Heart Muscle
}

\author{
BY C. GREENWOOD \\ Department of Biochemistry, University of Sheffield, Sheffield 10
}

(Received 23 July 1962)

The preparation described below was first found as a fraction appearing on digestion of a Keilin \& Hartree (1947) heart-muscle preparation with venom from Agkistrodon piscivorus (cotton-mouth moccasin), and a preliminary account of this has been given by Gibson, Greenwood \& Massey (1960). The material differs from other cytochromeoxidase preparations in being sufficiently clear to allow spectrophotometric studies without requiring the addition of cholate or detergents to bring it into solution. Although the preparation is much less active than that of Griffiths \& Wharton (1961), it compares well on a $Q_{\mathrm{O}_{2}}$ basis with most others in the literature and may be useful where wetting agents are especially undesirable. The present paper gives details of the method of preparation and analytical results for iron and copper, together with spectrophotometric data.

\section{MATERIALS}

Potassium chloroiridate was obtained from Johnson, Matthey and Co. Ltd., 78-83 Hatton Garden, London, E.C. 1. Sodium dithionite (not less than $85 \%$ ), ethylenediaminetetra-acetic acid (EDTA), ascorbic acid and 2,3dimercaptopropanol (BAL) were obtained from British Drug Houses Ltd., Poole, Dorset. Solutions of EDTA and ascorbic acid were neutralized with $\mathrm{NaOH}$ in making up to standard concentrations. All other chemicals used were of analytical reagent quality. Asolectin (purified soya phosphatides) was a gift from Associated Concentrates 